\title{
Can Schools and Education Policy Make Children Happier? A Comparative Study in 33 Countries
}

\author{
Jose Marquez $^{1}$ (D) $\cdot$ Gill Main ${ }^{1}$
}

Accepted: 21 July 2020 / Published online: 31 July 2020

(C) The Author(s) 2020

\begin{abstract}
Our understanding of child subjective well-being and how to promote it has improved substantially over the last decade. In relation to the role of education policy in shaping subjective well-being, although valuable research has been conducted, many questions remain unanswered. This paper aims to fill this gap by studying the links between education policy and students' life satisfaction. We use linear and multilevel regression to analyse PISA 2015 data on 15-year-old students in 33 countries. Our interest is in within society differences and how these vary across societies. We find that (1) there is an association between multiple education policy-relevant factors and students' life satisfaction, which is particularly prominent -and observed in a larger number of countries- in the domains of family relationships, schoolwork-related anxiety and bullying. Our models explain between one-fifth and one-third of the variation in students' life satisfaction. Results also indicate that (2) schools may play an important role in shaping students' life satisfaction. This is supported by evidence that these associations tend to vary by school; by evidence on the existence of school effects in all countries but two; and by the finding that a proportion - substantial in some countriesof the variation in students' life satisfaction is explained by differences between schools. Finally, we find that (3) in relation to both questions, there are important differences across societies. Overall, these results provide evidence that an association between education policy and children's subjective well-being seems to exist but is of a complex nature.
\end{abstract}

Keywords Subjective well-being $\cdot$ Life satisfaction $\cdot$ Education policy $\cdot$ PISA $\cdot$ Child wellbeing $\cdot$ Happiness

Jose Marquez

edjmm@leeds.ac.uk

Gill Main

G.Main@leeds.ac.uk

Extended author information available on the last page of the article 


\section{Background}

An increasing interest in subjective well-being (SWB) has been observed in recent decades. One motivation for this growing interest is the finding that beyond a certain level, increases in GDP do not translate into greater happiness (Easterlin 1974; Layard 2005). Since the recommendation by the Stiglitz Commission (Stiglitz 2009) that social progress should be assessed using SWB indicators, efforts to promote this have proliferated worldwide. At the international level, some examples are the creation by the OECD of the How is Life Index (OECD 2011, 2013, 2015, 2017c) and the publication of multiple World Happiness reports (Helliwell et al. 2012, 2013, 2015, 2016, 2017, 2018, 2019). At the national level, in the UK, the Office for National Statistics has created a programme to measure national well-being including the use of SWB indicators (Hicks et al. 2013). In some countries, SWB has gained importance in governments' agendas and nations such as Buthan (OPHI 2020) and the United Arab Emirates (UAE) (UAE Government 2020) have appointed Ministers of Happiness and declared happiness among its citizens a national goal to be pursued through government intervention.

In relation to children, this is a more recent phenomenon and the consideration of subjective indicators of child well-being in policymaking remains far less common. This is so despite the fact that it has been three decades since almost all countries worldwide recognised the United Nations Convention on the Rights of the Child (United Nations 1989), including children's right to be listened to and to have their views taken into consideration in all decisions affecting their lives (Article 12). Casas (2011) argues that this is mainly the result of the lack of political importance attributed to children's own perspectives. In academia, however, important progress has been made in recent years in understanding children's SWB and its links with policyrelevant domains. This is, in part, thanks to an increasing number of international studies including the Health Behaviour in School-aged Children study (Currie 2012) and, more recently, Children's Worlds (Rees and Main 2015). More recently, PISA 2015 (OECD 2017a) has incorporated questions on SWB, which represents a substantial improvement in terms of data availability. This is particularly relevant regarding the association between public policy and child SWB in an educational context, which remains under-researched. In this regard, PISA 2015 includes very rich information not only on students' life satisfaction (LS) and broader well-being but also on education policies and practices.

Education is one of the policy areas which is likely to influence children's SWB. Children spend a large amount of time at school and performing school-related activities, and school is often a major source of social interactions. For these reasons, school and education are deemed to impact the well-being of children in a wide range of domains. Studies of school life have traditionally focused on academic outcomes and well-becoming considerations (Ben-Arieh 2005) -that is, children's future outcomes in adulthood, rather than well-being in the present. The increasing acknowledgement of the importance of considering children's views on the things which affect their lives (Ben-Arieh 2008) highlights the importance of considering children's well-being in the context of education. This research aims to contribute to this goal by using subjective measures of child well-being in order to shed some light on the issue of whether schools and education policy can make children happier. 


\subsection{Conceptualising SWB}

SWB refers to 'a person's cognitive and affective evaluations of his or her life' (Diener et al. 2002). The cognitive dimension involves assessing satisfaction with one's life in general or with a particular aspect of life. The affective element refers to emotions, moods and feelings, which can be positive (e.g. joy, affection, confidence, etc.) and negative (anxiety, shame, anger, etc.). This highly influential conceptualisation by Diener (1984) informed the work by the Stiglitz Commission (Stiglitz 2009) and, for more than three decades, has remained as the main conceptual reference in research on SWB.

This paper focuses on the cognitive dimension of SWB, which is more stable over time than the affective dimension (Eid and Diener 2004). In particular, we focus on overall LS. LS is closely related to the notion of happiness, and multiple studies have used both terms interchangeably (e.g. Diener 1984; Diener et al. 1999). In research on children and adolescents, LS is also the most common indicator used by researchers to study SWB (Proctor et al. 2009).

\subsection{Explaining Variation in Child Subjective Well-Being}

One reason that child well-being has been more difficult to incorporate into policy considerations may be the common and widely challenged belief that children belong in the 'private realm' (Wyness 2014), with their parents being responsible for ensuring their well-being. Unquestionably, the factors shaping children's well-being will be different in some ways from those informing levels of adult well-being, as a result of their different experiences of the world. Some of these differences emerge as a result of children's dependence on families for the provision of care and resources; others result from their participation in different activities - e.g. school rather than work - compared to adults. For the purposes of this article, we draw on Bronfenbrenner's ecological systems theory (1978) to explore the variation in child well-being. This allows for the consideration of a wide range of influences on child well-being. The importance of family and immediate surroundings (microsystems) is an important proximal factor in understanding well-being, and it is complemented with simultaneous consideration of more distant influences, such as education policy. Besides, to better understand the role played by schools, the analysis focuses on two key elements of the student's most immediate environment (family and school) and how they interact to shape students' SWB in the mesosystem.

Turning to the literature investigating variation in subjective well-being, three main conclusions can be drawn. The first one is that differences in mean levels of child SWB across countries are significant (Klocke et al. 2014; Dinisman and Ben-Arieh 2016). In the case of adults, Helliwell et al. (2015) find that six nation-level factors - GDP per capita, social support, healthy life expectancy, freedom to make life choices, generosity of giving and perceptions of corruption- explain up to $74 \%$ of the variation in SWB between countries. However, in the case of children, nation-level factors rarely explain country differences in the mean level of SWB (Lee and Yoo 2015; Bradshaw and Rees 2017). In contrast, family, school and community significantly affect the levels of children's SWB (Lee and Yoo 2015). The second conclusion is, therefore, that most of the variation in child SWB seems to be explained by differences within countries rather 
than between countries (Lee and Yoo 2015; Bradshaw and Rees 2017; Klocke et al. 2014; Moreno 2017; Looze et al. 2018; Bradshaw 2015; Newland et al. 2018). The third important conclusion is that the factors that explain this variation at the national level -that is, micro- (individual, home) and meso-level (school, community) factorsand their relative importance in the shaping of child SWB, vary considerably from country to country (Lee and Yoo 2015; Bradshaw and Rees 2017). However, home, school and community factors are still significant predictors of children's SWB even after controlling for country-specific culture and context variables (Lee and Yoo 2015).

These and other studies show that many of the factors that explain variation in child SWB seem policy amenable. This observation begs the question of whether children's SWB can be influenced by education policy, a question which remains underresearched.

\subsection{Public Policy and Child Subjective Well-Being}

There are several reasons why we might not expect to find an association between public policy and children's SWB. Bradshaw (2015) provides a detailed discussion of potential reasons for this, noting that there is also increasing evidence that although an association may be hard to find, it is likely to exist. Most of this evidence refers to the links between children's SWB and domains of children's lives that seem policy amenable. Some of these public policy-relevant domains are discussed below. Since the focus of this paper is on education policy, we initially discuss education-specific factors which have been demonstrated to have (the potential to) relate to SWB. Following this, we provide brief details of other aspects of children's lives which, while not directly related to the school setting, may be subject to school-level interventions with the potential to realise improvements in children's SWB.

\subsubsection{School Life}

School is a domain of children's lives in which policy can make a clear difference. Using Children's Worlds data, Rees and Main (2015) show that there is a much higher degree of cross-country variability regarding children's feelings about school issues than in other domains such as health or safety. Their study also reveals that although overall SWB seems to decrease from age 10 to 12 , school is the area where this trend is most accentuated, with children from some countries experiencing a more substantial decrease in SWB than others.

Other research indicates that differences between schools - both obvious and more subtle - may be important. In a comparative study using data from England and the United States, Clair (2014) shows that the school a child attends may explain a considerable proportion of the variance in her SWB both in terms of affective wellbeing and LS.

Some factors within school life which have been identified as important in previous research include:

- The quality of relationships between teachers and the student has been found to decrease with age (Bokhorst et al. 2010; Demaray and Malecki 2003; Furman and Buhrmester 1992; García-Moya et al. 2014). Positive relationships with teachers are 
related to higher child SWB (Cotterell and Cotterell 2007; García-Moya et al. 2014; OECD 2017a; Moore et al. 2018; Newland et al. 2018; Danielsen et al. 2011; Diseth and Samdal 2014), higher satisfaction with school (Samdal et al. 1998), lower risk of initiation of health-risk behaviours (McNeely and Falci 2004; Moore et al. 2018) and lower risk of mental health problems (Moore et al. 2018).

- Relationships with school peers are also important. Multiple aspects of these relationships are associated with children's SWB. These include number of friends, frequency of interactions, satisfaction with friendships, perceiving that friends care about oneself; friendship group shared attitudes such as hope and positivity; and, particularly, bullying (Chu et al. 2010; Corsano et al. 2006; Gilman and Huebner 2003; Goswami 2012; Marshall 2004; Oberle et al. 2011; Proctor et al. 2010; Rose et al. 2014; Tiliouine 2015; Newland et al. 2018).

- The experience of bullying profoundly shapes children's experiences at school and it is of paramount importance to children's SWB. Bullying is negatively associated with factors such as school climate, peer and teacher support, liking school and -in particular- SWB (Martinez et al. 2011; Bradshaw et al. 2017; Kutsar and Kasearu 2017); and negative effects may impact both bullied and bullying students (Flaspohler et al. 2009; Navarro et al. 2015). The effects of bullying vary by gender, age and socio-economic status (Alikasifoglu et al. 2007; Bradshaw et al. 2017), and although bullying is a better predictor of SWB in rich than in poor countries (Bradshaw et al. 2017; Savahl et al. 2019) it is an important factor in understanding variation in children's well-being at school globally.

\subsubsection{Other Factors}

Other factors demonstrated to be associated with SWB include that school change is negatively associated with child SWB (Rees et al. 2012) and that children living in countries with more generous preschool education policies are more satisfied with their lives (Moreno 2017). More broadly, other factors which have been established as associated with SWB and which, while not directly school-related, are amenable to policy intervention at the level of the school, include:

- Local area: Feeling safe, access to resources and social connectedness have been found to positively relate to subjective well-being (Eriksson et al. 2011; Oberle et al. 2011; Kaye-Tzadok et al. 2017; Lee and Yoo 2015; Newland et al. 2015; Lawler et al. 2017; Newland et al. 2018).

- Health: Several health-related factors including physical fitness (positive association) and illness or disease (negative association) have been found to relate to children's LS (Marques et al. 2017; Klocke et al. 2014; Kleszczewska et al. 2018; Haanpää et al. 2018; Lew et al. 2018).

- Time use (including ICT use): Time use, particularly in relation to ICT use, has been found to predict variation in LS, and also varies according to gender, thus potentially explaining gender differences in LS (Rees 2017; Larson and Verma 1999; Amin and Chandrasekhar 2012; Ersado 2005; Dornan and Woodhead 2015; Iannotti et al. 2009; Fergusson et al. 2015; Boniel-Nissim et al. 2015) 
- Rights: Children's awareness of their rights as children and, especially, perceiving that these rights are respected by adults are positively associated with SWB (Casas et al. 2018).

- Gender and sexuality: Gender differences are common in studies of SWB (Rees and Main 2015). Furthermore, there is evidence from Iceland that adolescents from sexual minority groups report lower LS (Thorsteinsson et al. 2017). This would call for the development of programmes oriented to promote LGBTQI+ rights in schools and the wider society.

- Body image: Satisfaction with body images strongly relates to gender and has been found to impact SWB (Rees and Main 2015).

- Home context and relationships within the family: Home environment and family relationship quality are frequently found to be among the most important predictors of SWB (Lawler et al. 2017; Powdthavee and Vernoit 2013; Klocke et al. 2014; Oberle et al. 2011; Rose et al. 2014; Chu et al. 2010; Gilman and Huebner 2003; Goswami 2012; Govender et al. 2014; Proctor et al. 2010; Moore et al. 2018; Newland et al. 2018; González et al. 2015; Rees et al. 2012).

\subsection{Approach and Research Questions}

Based on the above literature and evidence review, we adopt the following approach to studying the links between education policy and students' LS. First, we focus on education policy-relevant factors and how these are associated with students' LS. We then go on to look at the effects of schools on LS. Finally, we examine differences between countries in terms of the association between education policy and student LS. This comparative approach is not concerned with explaining country differences based on nation-level characteristics. Instead, we focus on micro- (student, home) and meso-level (school) characteristics and cross-society differences in how these factors influence students' LS.

We hypothesise that (1) there is an association between education policy-relevant dimensions and students' LS; that (2) schools play an important role in shaping students' LS; and that (3) differences across societies regarding the links between education policy and students' LS are significant. We examine these hypotheses in view of the following research questions:

1. Is there an association between education policy-relevant dimensions and students' LS?

2. Does this association vary by school? Are there school effects on students' LS? What proportion of the variation in students' LS is explained by differences between schools?

3. Does the association between education policy and students' LS vary across societies?

\section{Methods and Data}

\subsection{Pisa 2015}

In this paper, we use data from PISA 2015, which is the most recent PISA study available, released in 2017. PISA is a worldwide study by the OECD on member and 
non-member countries and economies. This study is carried out every 3 years and focuses on 15-year-old students' performance in mathematics, science, and reading. It also includes information on students' socioeconomic status, and education policies and practices. Since 2015, it also collects information on a wider range of well-being domains, including students' LS. In addition to student-supplied data, PISA also gathers information from parents, teachers and school principals on a large number of issues affecting the lives of these children. Each student and school have their own identifier. This allows researchers to conduct multilevel analyses, an essential tool to study the association between education policy and students' SWB.

PISA 2015 LS questions were asked in 47 of the 72 participating countries. Countries included in this study were selected based on the inclusion of key questions, and on the levels of missing data in variables of interest. 33 countries were selected for inclusion on this basis: Austria, Bulgaria, Chile, China, Colombia, Croatia, Czech Republic, Estonia, Finland, France, Greece, Hong Kong, Hungary, Ireland, Iceland, Luxembourg, Latvia, Mexico, Peru, Poland, Portugal, Qatar, Russia, Slovakia, Slovenia, South Korea, Spain, Switzerland, Taiwan, Thailand, Turkey, the UAE, and the United States. For the sake of simplicity and to facilitate the reading, throughout this paper, we refer to all of them as countries regardless of the status of Hong Kong and Taiwan and the coverage of the data sample in the case of China, where only the regions and cities of Beijing, Shanghai, Jiangsu and Guangdong (B-S-J-G from now on) participated in PISA 2015.

\subsection{Variables}

Our dependent variable is overall LS as defined in PISA 2015 (see Appendix 1). As independent variables, we considered all those enumerated in Table 1. Some of these variables are derived from information collected from students (student-level variables) and others from information collected from school principals (schoollevel variables). Most of these variables were selected due to their relevance to education policy and practice. Nonetheless, there are important differences in the extent to which these factors can be considered to be amenable to policy interventions. For most of them, it is easy to see how policy could influence these factors (bullying, school anxiety, school resources, grade repetition, etc.). In other cases, the capacity of policy to influence these factors might appear more questionable. This is the case of valuing cooperation and teamwork, for example, which may be related to personality and, therefore, difficult to shape by policy. However, there is some evidence suggesting that schools may promote more positive attitudes towards cooperation (Glăveanu et al. 2016; Gillies 2004). Another important example is feeling emotionally supported by parents in relation to school. In this case, however, the items behind this variable (my parents are interested in my school activities; my parents support my educational efforts and achievements; my parents support me when I am facing difficulties at school; my parents encourage me to be confident) suggest that -although indirectly- students' feelings regarding their parents' support in relation to school could perfectly be influenced by education policy interventions intended to promote parents' involvement in the school and there is a large body of research studying possible strategies to facilitate this (Park and Holloway 2013; Bouakaz 2007). 
In addition, a few independent variables are not policy-relevant but were included either because these are considered essential control variables (SES and gender) and/or because they can provide good insights into factors which may shape students' LS and which serve as an important reference to compare the relative importance of the effects of education policy-relevant factors in students' LS (certain time-use variables, the population size of the community where the school is located).

In some cases, we used the original PISA 2015 variable. In others, some transformations were performed. This information is detailed in Appendix 1. Appendix 1 also provides information on the specific PISA 2015 items used to derive these measures.

\subsection{Analysis}

We first conducted a descriptive analysis to report the mean level of students' LS and the degree of skewness of this variable for each country. The implications of working with skewed data are discussed later in this paper. Then we estimated three linear regression models - model 1 (sociodemographic variables only), model 2 (incorporating self-reported well-being variables) and model 3 (full model, which includes all the independent variables) to report the adjusted $\mathrm{R}$-squared. This figure indicates the proportion of variation in students' LS that is explained by the variables considered in the model (note for the multilevel models we report the R-squared as proposed by Snijders and Bosker (1994: 350-354), also see Snijders and Bosker (1999: 99-105).

We then went on to perform multilevel modelling. First, we estimated a null model to provide a "benchmark" (Hox 2010, pg 56) deviance value and allow for the calculation of the intra-class correlation (ICC) / variance partition coefficient (VPC), which provide an estimate of the proportion of variation in students' LS that is explained at student and school level. Then we created two two-level multilevel regression models for each country. The first model (Model 1) only considers student-level predictors and the second one (Model 2) considers both student- and school-level predictors. In this process, we used a topdown strategy to define the fixed part of the model (see Hox 2010, pg. 55; West et al. 2007) where non-statistically-significant variables (except essential control variables: gender and SES) were not retained. With these models we studied: the direct effects of independent variables in students' LS; the existence of school effects in students' LS; the school random effects to determine whether the association between education policy-relevant factors and students' LS varies by school; and the VPCs which, as noted before, indicate the proportion of variation in students' LS that is explained by differences between schools. As mentioned above, the difference between student-level and schoollevel independent variables is that the former were collected at the student-level (i.e. information provided by the student) and the latter at the school-level (i.e. information provided by the School Principal). However, in terms of the analysis, the role of schools is not assessed in view of the direct effect of student- and school-level variables but in terms of the school effects, random effects and the VPV values as described above.

To estimate our multilevel models, we used maximum likelihood (ML) instead of restricted maximum likelihood (REML). Although REML methods 
Table 1 List of variables

\begin{tabular}{|c|c|c|c|c|}
\hline \multirow[t]{2}{*}{ Group } & \multirow[t]{2}{*}{ Variable } & \multicolumn{3}{|l|}{ Details } \\
\hline & & $\begin{array}{l}\text { Type } \\
\text { of variable }\end{array}$ & Categories & $\begin{array}{l}\text { Number of } \\
\text { countries } \\
\text { with } \\
\text { available } \\
\text { data }\end{array}$ \\
\hline & $\begin{array}{l}\text { Life satisfaction } \\
\quad(0-10)\end{array}$ & Continuous & - & 33 \\
\hline \multirow[t]{2}{*}{ Sociodemographic } & Gender (girl) & Dichotomous & Girl; boy & 33 \\
\hline & $\begin{array}{l}\text { Index of } \\
\text { socioeconomic } \\
\text { status }\end{array}$ & Continuous & - & 33 \\
\hline \multirow{6}{*}{$\begin{array}{r}\text { Self-reported } \\
\text { well-being }\end{array}$} & Index of & & schoolwork-related anxiety & Continuous \\
\hline & - & & & \\
\hline & & 33 & & \\
\hline & $\begin{array}{l}\text { Index of sense of } \\
\text { belonging at } \\
\text { school }\end{array}$ & Continuous & - & 33 \\
\hline & $\begin{array}{l}\text { Index of frequency } \\
\text { of suffering } \\
\text { bullying }\end{array}$ & Continuous & - & 33 \\
\hline & $\begin{array}{l}\text { Index of feeling } \\
\text { unfairly treated by } \\
\text { teachers }\end{array}$ & Continuous & - & 33 \\
\hline $\begin{array}{l}\text { Index of feeling } \\
\text { emotionally } \\
\text { supported by } \\
\text { parents }\end{array}$ & Continuous & - & 33 & \\
\hline \multirow[t]{6}{*}{$\begin{array}{c}\text { Time use, habits, } \\
\text { ICT use }\end{array}$} & $\begin{array}{l}\text { Worked in the } \\
\text { household or took } \\
\text { care of other } \\
\text { family members }\end{array}$ & Categorical & $\begin{array}{l}\text { Did not do it in the previous day; } \\
\text { did it before or after school; did it } \\
\text { before and after school }\end{array}$ & 33 \\
\hline & Worked for pay & Categorical & & 33 \\
\hline & $\begin{array}{l}\text { Studied for school or } \\
\text { homework }\end{array}$ & Categorical & & 33 \\
\hline & $\begin{array}{c}\text { Read a book / news- } \\
\text { paper / magazine }\end{array}$ & Categorical & & 33 \\
\hline & Played videogames & Categorical & & 33 \\
\hline & Watched & & & \\
\hline
\end{tabular}

TV $/<$ DVD $>$ /VideoCategorical

$33 \mathrm{Met}$ friends or talked to friends on the phoneCategorical

33 Internet / Chat / Social networks (e.g. Facebook)Categorical

33 Talked to parentsCategorical

33 Had breakfastDichotomousDid it in the previous day; did not do it

$33 \mathrm{Had}$ dinnerDichotomous

33Days of vigorous exercise outside school last weekCategorical0; $1 ; 2 ; 3 ; 4 ; 5 ; 6 ; 7$

33Learning time at school (minutes per week)Continuous-

33Out-of-school study time per week (hours)Continuous- 
33 Index of time spent using ICT at school in generalContinuous-

29Index of time spent using ICT outside school for schoolworkContinuous-

29 Index of time spent using ICT at home for leisureContinuous-

29Other student-level variablesIndex of valuing cooperationContinuous-

33 Index of academic competenceContinuous-

33 Index of truancyContinuous-

33Education programme attendedCategoricalGeneral; pre-vocational; vocational; modular

33 Having repeated a grade at least onceDichotomousYes; no

33 Years attended pre-primary educationCategoricalLess than 1 year; 1 year or more but less than 2 years;

2 years or more but less than 3 years; 3 years or more but less than 4 years; 4 years or more but less than

5 years; 5 years or more

33 School-level variablesSize of the community where the school is locatedCategoricalFewer than 3000 people; 3000 to about 15,000 people; 15,000 to about 100,000 people; 100,000 to about 1,000,000 people; More than $1,000,000$ people

33School typeCategoricalPublic school (publically funded and run); semi-private school (publically funded but privately run); private school (privately funded and run).

33School size (total school enrolment)Continuous-

32 Average class size in the schoolContinuous-

33 Index of shortage of material and human school resourcesContinuous-

33 Student / teacher ratioContinuous-

33 Percentage of certified teacher in the schoolContinuous-

32 Index of teachers' behaviour hindering teachingContinuous-

33 School practices ability grouping within classesDichotomousYes; no

33 School practices ability grouping between classesDichotomous Yes; no 33

tend to produce better estimates, particularly when the number of groups is small (Hox 2010), REML is not compatible with applying sample weights in multilevel models in Stata, which is an unavoidable requirement in the analysis of PISA data. In PISA studies, certain schools/students often are over/undersampled for different reasons. For instance, in Australia, indigenous children are over-sampled to allow tracking progress of students of this minority group. To account for sampling and non-response consideration, PISA's data sets include a series of weights that need to be applied to avoid getting biased estimates. Laukaityte and Wiberg (2018) argue that although all international large-scale assessment databases (including PISA studies) include ready-to-use scaled weights and their components, these weights have been designed to use in single-level analysis and are not adequate to use in multilevel analysis. In PISA 2015 -as in other OECD datasets- final student weights need to be scaled in multilevel analyses (for a detail discussion, see Laukaityte and Wiberg 2018). In this paper, we do this using the scale method presented by Rabe-Hesketh and Skrondal (2006).

All variables were checked for missing data, and as noted above we focused our analysis on those countries where levels of missing data in variables of interest are acceptable - this is well below $20 \%$ in most cases. Information on ICT use variables in Qatar, Turkey, the UAE and the USA, school size in Austria, and the proportion of certified teachers in Hungary is $100 \%$ missing In the case of these countries, these variables were not considered in the models. For all variables, we use listwise deletion, which is common in multilevel analyses using PISA data (Schirripa et al. 2018; Tsai et al. 2018; van Hek et al. 2018; Da Silva and Matos 2017). 


\section{Results}

\subsection{Basic Descriptive Information and Model Specifications}

Table 2 shows, for each country, the mean level of students' LS, the degree of skewness of this variable and the number of participating students and schools. Overall, there is great cross-country variation. Students' LS is the highest in Mexico, but there is not a clear cluster of countries where students' LS seems to be higher. By contrast, it seems clear that students from Eastern Asian societies -South Korea, Hong Kong, Taiwan, China (B-J-J-G)- tend to report relatively lower levels of LS. Students' LS is the lowest in Turkey. As it is commonly observed in the field, LS is negatively skewed and this is particularly accentuated in Mexico (see later discussion of this).

Table 3 shows some specifications of the regression models. In relation to our research questions, it seems that education-policy relevant factors may explain an important proportion of the variation in students' LS. In view of the results of the adjusted R-squared in the linear regression models and the R-squared -as defined by Snijders and Bosker (1994)- in the multilevel models, the variables that we examined would explain, approximately, between one-fifth and one-third of the variation in students' LS in the countries analysed. A closer look at the results of the adjusted Rsquared in the 3 linear regression models shows that socio-demographic variables (gender and SES) explain a rather small proportion of this variation. Most of this variation is explained by self-reported well-being variables -all of which are policyrelevant- and, to a lesser extent, the remaining independent variables, most of which are also policy-relevant. Differences across countries are significant. For instance, these variables explain up to $36 \%$ of the variation in students' LS in Iceland but only $15 \%$ in Bulgaria and the relative importance of these groups of variables in relation to students' LS also varies by country.

For all countries, results indicate that schools may influence students' LS. This is supported first by the results of the LR tests, which provide evidence of school effects (on 1 d.f., LR > 3.84) in all countries but Finland and Greece, where a multilevel model would not necessarily be preferred to a single-level model. And second, the VPC estimates indicate the proportion of the variance in students' LS that can be attributed to differences between schools. In the full model (model 2), the proportion of the variance in students' LS that is found to be explained at school level is above 5\% in 24 countries and is particularly high in 5 Eastern European countries: the Czech Republic (45.98\%), Estonia (42.41\%), Slovakia (40.49\%), Latvia (35.58\%) and Poland (24.43\%). Again, as in the case of the adjusted R-squared estimates discussed before, cross-country differences in terms of both the LR tests and VPC estimates are also important, indicating that the links between schools and education policy and students' LS vary substantially across countries.

\subsection{Direct Effects}

Table 4 presents a summary of the different direct effects studied in model 2 in the 33 countries analysed. Results show that whereas for some predictors a statistically significant effect is found in almost all the countries, for others, a statistically significant effect is found in a much smaller number of societies. In addition, the effect size varies 
Table 2 Life satisfaction descriptive information and number of students and school

\begin{tabular}{|c|c|c|c|c|}
\hline & \multicolumn{2}{|c|}{ Life satisfaction } & \multirow[t]{2}{*}{ Number of students } & \multirow[t]{2}{*}{ Number of schools } \\
\hline & Mean & Skewness & & \\
\hline Austria & 7.55 & -1.13 & 7007 & 263 \\
\hline Bulgaria & 7.42 & -0.94 & 5928 & 180 \\
\hline Chile & 7.45 & -0.90 & 7053 & 226 \\
\hline China (B-S-J-G) & 6.97 & -0.59 & 9841 & 268 \\
\hline Colombia & 7.77 & -1.23 & 11,795 & 371 \\
\hline Croatia & 7.90 & -1.32 & 5809 & 160 \\
\hline Czech Republic & 7.05 & -0.79 & 6894 & 333 \\
\hline Estonia & 7.49 & -1.03 & 5587 & 206 \\
\hline Finland & 7.88 & -1.36 & 5882 & 162 \\
\hline France & 7.63 & -1.03 & 6108 & 251 \\
\hline Greece & 6.92 & -0.79 & 5532 & 210 \\
\hline Hong-Kong & 6.49 & -0.64 & 5359 & 138 \\
\hline Hungary & 7.19 & -0.95 & 5658 & 245 \\
\hline Iceland & 7.79 & -1.32 & 3371 & 124 \\
\hline Ireland & 7.85 & -0.98 & 5741 & 167 \\
\hline Latvia & 7.36 & -0.95 & 4869 & 250 \\
\hline Luxembourg & 7.38 & -1.04 & 5299 & 44 \\
\hline Mexico & 8.26 & -1.55 & 7568 & 275 \\
\hline Peru & 7.49 & -0.96 & 6971 & 281 \\
\hline Poland & 7.19 & -0.90 & 4478 & 169 \\
\hline Portugal & 7.36 & -0.88 & 7325 & 246 \\
\hline Qatar & 7.42 & -0.94 & 12,083 & 167 \\
\hline Russia & 7.74 & -1.08 & 6036 & 210 \\
\hline Slovakia & 7.47 & -0.99 & 6350 & 280 \\
\hline Slovenia & 7.21 & -0.91 & 6406 & 301 \\
\hline South Korea & 6.36 & -0.44 & 5581 & 168 \\
\hline Spain & 7.44 & -1.11 & 6736 & 201 \\
\hline Switzerland & 7.65 & -1.21 & 5860 & 227 \\
\hline Taiwan & 6.61 & -0.44 & 7708 & 214 \\
\hline Thailand & 7.67 & -0.87 & 8249 & 273 \\
\hline Turkey & 6.11 & -0.37 & 5895 & 187 \\
\hline UAE & 7.30 & -0.80 & 14,167 & 470 \\
\hline United States & 7.36 & -0.87 & 5712 & 176 \\
\hline
\end{tabular}

for different countries. The direction of the effect also varies, with some effects being universally positive or negative, and others varying between different countries.

The following sections present a more detailed account of the results by country and group of variables. 


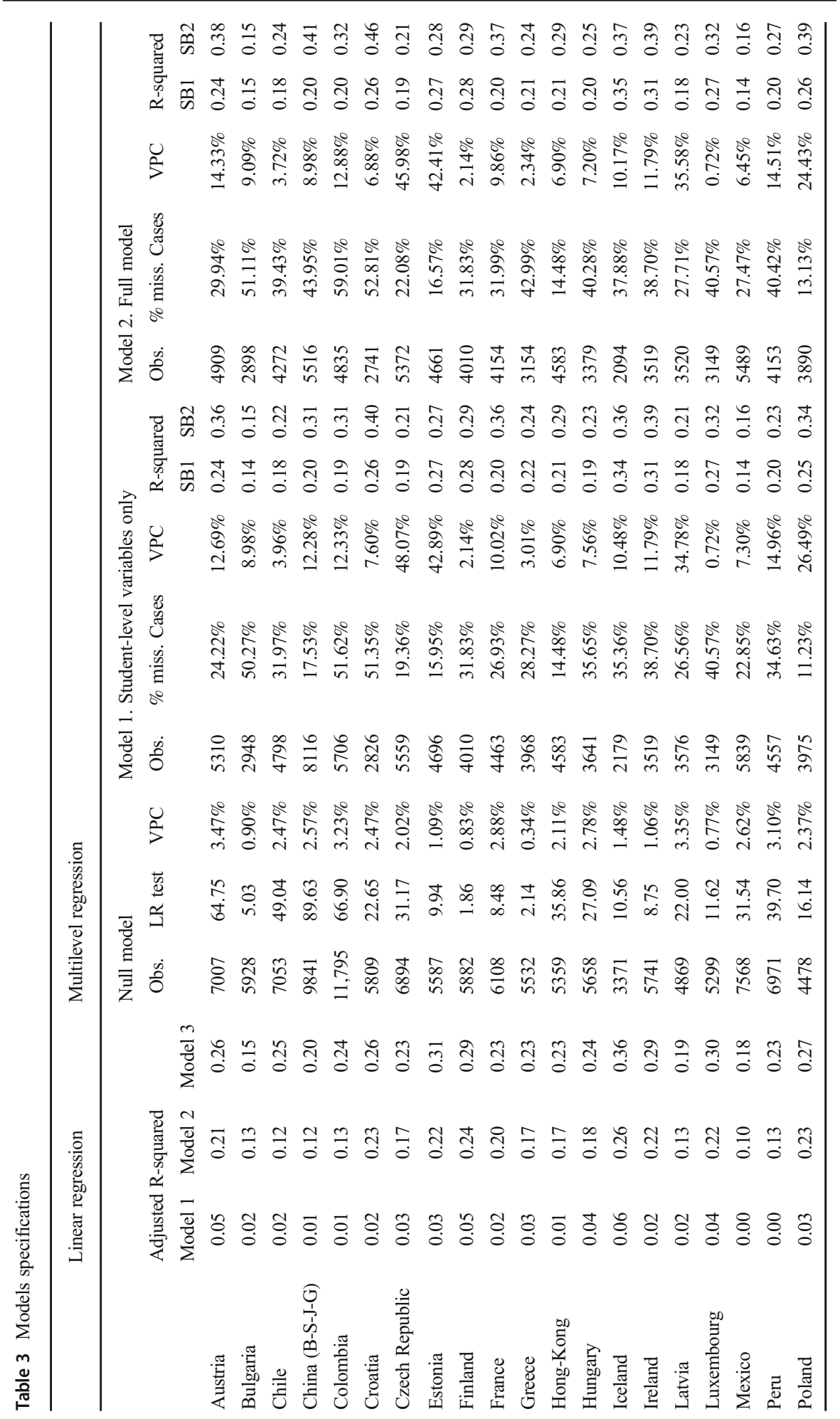




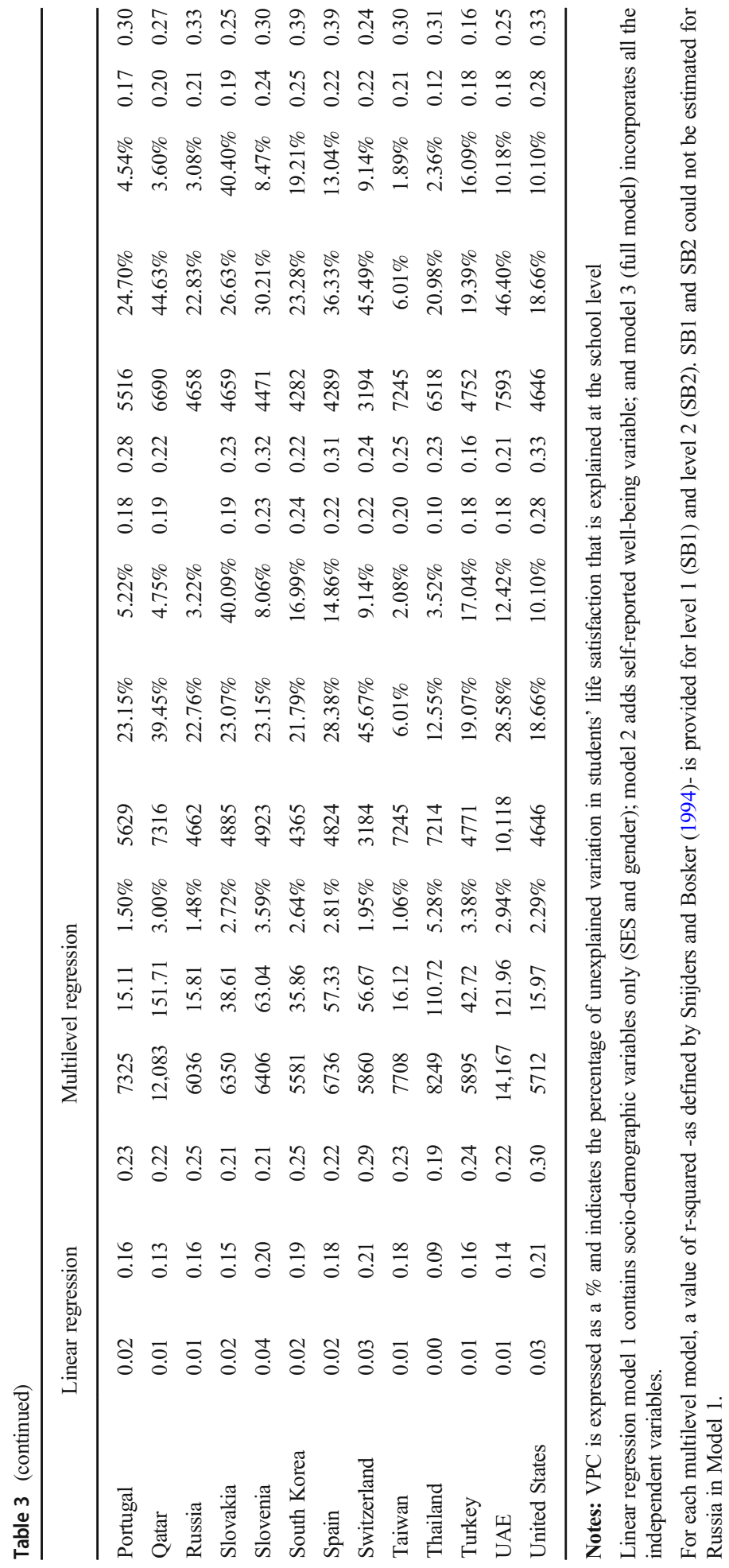


Table 4 Summary table of the effect of all predictor variables in the full ML model (model 2)

\begin{tabular}{|c|c|c|c|c|c|}
\hline \multirow[b]{2}{*}{ Girl } & \multirow{2}{*}{$\begin{array}{l}\text { Number of countries with } \\
\text { available data } \\
33\end{array}$} & \multicolumn{2}{|c|}{$\begin{array}{l}\text { Number of } \\
\text { countries } \\
\text { where a } \\
\text { statistically } \\
\text { significant } \\
\text { effect is } \\
\text { found }\end{array}$} & \multicolumn{2}{|c|}{$\begin{array}{l}\text { Mean effect } \\
\text { size* }^{*}\end{array}$} \\
\hline & & & $28(-)$ & & -0.43 \\
\hline Index of socioeconomic status (SES) & 33 & $\begin{array}{r}17(+ \\
)\end{array}$ & $1(-)$ & 0.15 & -0.09 \\
\hline Index of schoolwork-related anxiety & 33 & & $33(-)$ & & -0.34 \\
\hline Index of sense of belonging at school & 33 & $\begin{array}{r}14(+ \\
)\end{array}$ & & 0.13 & \\
\hline Index of frequency of suffering bullying & 33 & & $32(-)$ & & -0.28 \\
\hline Index of feeling unfairly treated by teachers & 33 & & $26(-)$ & & -0.19 \\
\hline $\begin{array}{l}\text { Index of feeling emotionally supported by parents in } \\
\text { relation to school }\end{array}$ & 33 & $\begin{array}{r}33(+ \\
)\end{array}$ & & 0.53 & \\
\hline $\begin{array}{l}\text { Worked in the household or took care of other family } \\
\text { members }\end{array}$ & 33 & $5(+)$ & $1(-)$ & $|0.19|$ & $-|0.33|$ \\
\hline Worked for pay & 33 & $5(+)$ & & $|0.21|$ & $-|0.70|$ \\
\hline Studied for school or homework & 33 & $\begin{array}{r}14(+ \\
)\end{array}$ & & $|0.20|$ & $-|0.63|$ \\
\hline Read a book/newspaper/magazine & 33 & $1(+)$ & $1(-)$ & $|0.24|$ & $-|0.39|$ \\
\hline Played videogames & 33 & $2(+)$ & $1(-)$ & $|0.15|$ & $-|0.40|$ \\
\hline Watched TV $/<$ DVD $>/$ Video & 33 & $3(+)$ & & $|0.23|$ & $-|0.70|$ \\
\hline Met friends or talked to friends on the phone & 33 & $7(+)$ & & $|0.18|$ & $-|0.45|$ \\
\hline Internet/Chat/Social networks (e.g. $<$ Facebook>) & 33 & & $2(-)$ & $|0.32|$ & $-|0.60|$ \\
\hline Talked to parents & 33 & $\begin{array}{r}24(+ \\
)\end{array}$ & & $|0.37|$ & $-|1.44|$ \\
\hline Had breakfast & 33 & $\begin{array}{r}25(+ \\
)\end{array}$ & & 0.39 & \\
\hline Had dinner & 33 & $4(+)$ & & 0.59 & \\
\hline Days of vigorous exercise outside school last week & 33 & $\begin{array}{r}22(+ \\
)\end{array}$ & & $|0.20|$ & $-|0.73|$ \\
\hline Learning time at school (minutes per week) & 33 & $3(+)$ & & 0.12 & \\
\hline Out-of-school study time per week (hours) & 33 & $2(+)$ & & 0.15 & \\
\hline Index of time spent using ICT at school in general & 29 & $3(+)$ & & 0.15 & \\
\hline $\begin{array}{l}\text { Index of time spent using ICT outside school for } \\
\text { schoolwork }\end{array}$ & 29 & $7(+)$ & & 0.14 & \\
\hline Index of time spent using ICT at home for leisure & 29 & $1(+)$ & $2(-)$ & 0.12 & -0.15 \\
\hline Index of academic competence & 33 & & $21(-)$ & & -0.18 \\
\hline Index of truancy & 33 & & $16(-)$ & & -0.14 \\
\hline Index of valuing cooperation & 33 & $\begin{array}{r}28(+ \\
)\end{array}$ & & 0.18 & \\
\hline Having repeated a grade at least once & 33 & & $2(-)$ & & -0.40 \\
\hline Years attended pre-primary education & 33 & & $3(-)$ & $|0.43|$ & $-|1.14|$ \\
\hline Education programme attended & 33 & & $2(-)$ & $|0.21|$ & $-|0.30|$ \\
\hline School type & 32 & & & $|0.16|$ & $-|1.23|$ \\
\hline Size of the community where the school is located & 33 & $9(-)$ & $1(+)$ & $|0.29|$ & $-|0.76|$ \\
\hline
\end{tabular}


Table 4 (continued)

\begin{tabular}{|c|c|c|c|c|c|}
\hline \multirow[b]{2}{*}{ Girl } & \multirow{2}{*}{$\begin{array}{l}\text { Number of countries with } \\
\text { available data } \\
33\end{array}$} & \multicolumn{2}{|c|}{$\begin{array}{l}\text { Number of } \\
\text { countries } \\
\text { where a } \\
\text { statistically } \\
\text { significant } \\
\text { effect is } \\
\text { found }\end{array}$} & \multicolumn{2}{|c|}{$\begin{array}{l}\text { Mean effect } \\
\text { size* }\end{array}$} \\
\hline & & & $28(-)$ & & -0.43 \\
\hline School size (total school enrolment in hundreds) & 32 & $1(+)$ & $6(-)$ & 0.04 & -0.02 \\
\hline Average class size in the school & 33 & $2(+)$ & $2(-)$ & -0.02 & 0.02 \\
\hline $\begin{array}{l}\text { Index of shortage of material and human school } \\
\text { resources }\end{array}$ & 33 & & $1(-)$ & & -0.15 \\
\hline Student / teacher ratio & 33 & & $4(-)$ & & -0.03 \\
\hline Percentage of certified teacher in the school & 32 & $2(+)$ & & 0.54 & \\
\hline Index of teachers' behaviour hindering teaching & 33 & & $3(-)$ & & -0.12 \\
\hline School practices ability grouping within classes & 33 & $1(+)^{\prime}$ & $1(-)$ & 0.19 & -0.29 \\
\hline School practices ability grouping between classes & 33 & & $1(-)$ & & -0.18 \\
\hline
\end{tabular}

*For continuous and dichotomous predictors, the mean effect in those countries where this is significant is provided. For categorical variables (effect size in italics), a range of the effect size (expressed in absolute terms) across different categories and countries and economies is provided

\subsubsection{Socio-Demographic Variables}

Girls report statistically lower LS in almost all the countries analysed (see Tables 4 and 8 in Appendix 2). The effect is greater than 0.4 points in half of them and above 0.7 in Luxembourg, Slovenia and Austria.

SES is positively associated with students' LS in 17 countries. The size of the effect of an increase of 1 standard deviation in the index of SES is between 0.1 and 0.2 points in the majority of cases. Interestingly, in Slovenia, this association is negative $(-0.09$ points).

\subsubsection{Self-Reported Well-Being Variables}

Self-reported well-being strongly relates to students' LS. Tables 4 and 8 in Appendix 2 show that there are three predictors whose effect on students' LS is found in almost all countries: schoolwork-related anxiety, frequency of bullying (with the only exception of South Korea, where this effect is not statistically significant), and feeling emotionally supported by parents in relation to school. The greatest effect size relates to feeling emotionally supported by parents in relation to school -the effect of an increase of 1 standard deviation in this index ranges between 0.4 and 0.7 points. The effect size is smaller (between 0.2 and 0.4 in most cases) for indices of frequency of bullying and schoolwork-related anxiety -although, in the latter case, it seems somewhat greater overall and particularly great (around 0.6 points) in South Korea and Iceland.

The other self-reported well-being variables seem somewhat less important to students' LS. In 26 countries, feeling unfairly treated by teachers is negatively 
associated with students' LS. However, compared to the self-reported well-being variables mentioned above, the size of the effect is smaller (between 0.15 and 0.25 points in most countries). For sense of belonging at school, the association is positive and found in a smaller number of countries (14) and the size of the effect is smaller on average (between 0.1 and 0.2 points in most).

\subsubsection{Effect of Time Use, Health Habits and ICT Use Variables}

Multiple variables that refer to students' time use and health habits are associated with their LS. For ICT use variables, evidence of an association is more scarce overall. This information is detailed in Tables 4 and 9 in Appendix 2. In particular, talking to parents is a very important predictor of students' LS. In 24 countries, those who report having talked to their parents in the day before report much higher life satisfaction than those who do not. Moreover, LS is higher among those who do it before and after school than among those who do it either before or after school only. The effect size is above 0.40 points in most countries and is of at least 1.00 points in the UAE, Chile, Spain, Iceland, Mexico, and the United States. Other predictors of LS observed in many countries are eating breakfast before going to school, doing vigorous exercise outside the school in the previous week and studying for school or homework.

For the other time use, health habits and ICT use variables analysed, the picture is more complex. Overall, a statistically significant association is found in a smaller number of countries. There is heterogeneity in terms of both the size and sign of the effect. In some cases, although a statistically significant effect is found in just a few societies the effect size is great in some. This is the case, for instance, of watching TV/DVD/video in Turkey (between 0.59 and 0.70 points) and having dinner in Austria (0.56 points), Colombia (0.63 points), Czech Republic (0.51 points), and Ireland (0.66 points). Moreover, for a few of these other variables, a positive effect is found in some countries and a negative one in others.

\subsubsection{Effect of Other Student-Level Variables}

Some of the remaining variables measured at the student-level that we considered in this study seem related to students' LS in most countries (see Tables 4 and 10 in Appendix 2). First, students that have more positive attitudes towards cooperation and teamwork seem to report higher LS. The effect of an increase of 1 standard deviation in the index of valuing cooperation is associated with higher LS in 28 countries, and the effect size is around 0.2 points in most of them. Interestingly, the association between academic competence and students' LS is negative. This negative association is found in 20 countries and the effect size is also around 0.2 in the majority of them. By contrast, truancy seems to have a negative effect on students' LS. A negative association is found in 16 countries and the size of the effect ranges between 0.1 and 0.2 points.

For the other variables of this group, evidence of an association is much scarce. Having repeated a grade, the education programme the student attends, and pre-primary education attendance relate to students' LS in a few countries only. 


\subsubsection{Effect of School-Level Variables}

We find that for most of the predictor variables measured at the school level that we study, an association with students' LS is found in a small number of countries (see Tables 4 and 11 in Appendix 2). The main exception is school type. In 14 out of the 31 countries where there is more than one type of school, LS is associated with school type (i.e. either public, semi-private or private), and the effect size tends to be great (i.e. near or above 0.4 points in most cases). The population size of the community where the school is located is also important in some countries. In 10 of them, students attending schools located in small communities (fewer than 3000 people) report higher LS than those living in bigger communities. The effect size varies across societies and population categories and ranges between 0.29 and 0.76 points.

For all the other predictor variables measured at the school level, the picture is, again, less clear. In all of them, a statistically significant effect is found in a small number of societies. Moreover, for a few variables, the effect is positive in some societies and negative in others. The effect size tends to be small, although there are some exceptions. For example, the percentage of certified teachers seems to be important to students' LS in Greece and South Korea, which are the only two countries where an association is found. The size of the effect in these two countries is great, 0.36 and 0.73 points, respectively.

\subsection{Random Effects}

In these multilevel regression models, in order to assess how schools may influence students' LS, we also examined the existence of school random effects regarding schoolwork-related anxiety, the frequency of suffering bullying, feeling emotionally supported by parents in relation to school and having repeated a grade at least once. Table 5 shows evidence of random effects in relation to these factors in 16, 29, 26 and 14 countries, respectively. The estimates not reported (in blank) indicate that the random effect was not considered because it did not improve the model fit. Among those considered, statistically significant random effects are highlighted in bold. The existence of random effects would mean that differences in how schools deal with students with different characteristics (i.e. reporting different levels of schoolworkrelated anxiety, frequency of suffering bullying and feeling emotionally supported by parents in relation to school; and those who have and have not repeated a grade at least once) has a significant impact on their LS.

In 5 Eastern European countries -Czech Republic, Estonia, Latvia, Poland and Slovakia- the school random effect coefficient for grade repetition is above 1 point. This means that among those students who have repeated a grade in these countries -a total of $4.03 \%, 3.34 \%, 4.23 \%, 4.16 \%$ and $5.88 \%$, respectively- attending to one school or another makes a big difference to their LS. These exact same countries happen to be the countries with very high VPC values - this is the countries where schools influence students' LS the most (see section 3.1 and Table 3 above). In the null-model, these Eastern European countries did not stand out in terms of the VPC. However, when adding predictor variables (including random effects) to the model (i.e., model 1 and model 2), VPCs in these nations increase dramatically. Indeed, when removing school random effects for grade repetition from model 2, VPCs in Czech Republic, Estonia, 


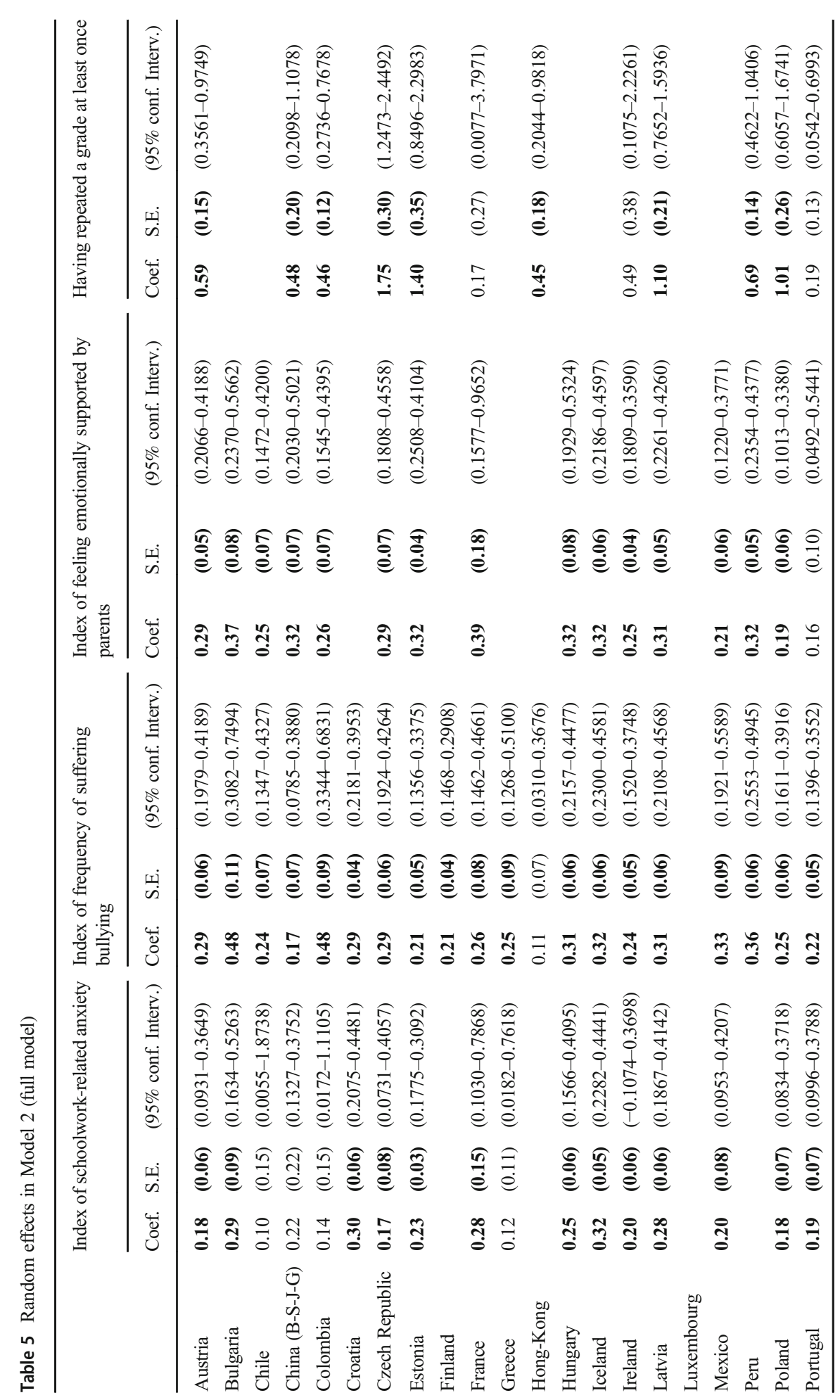




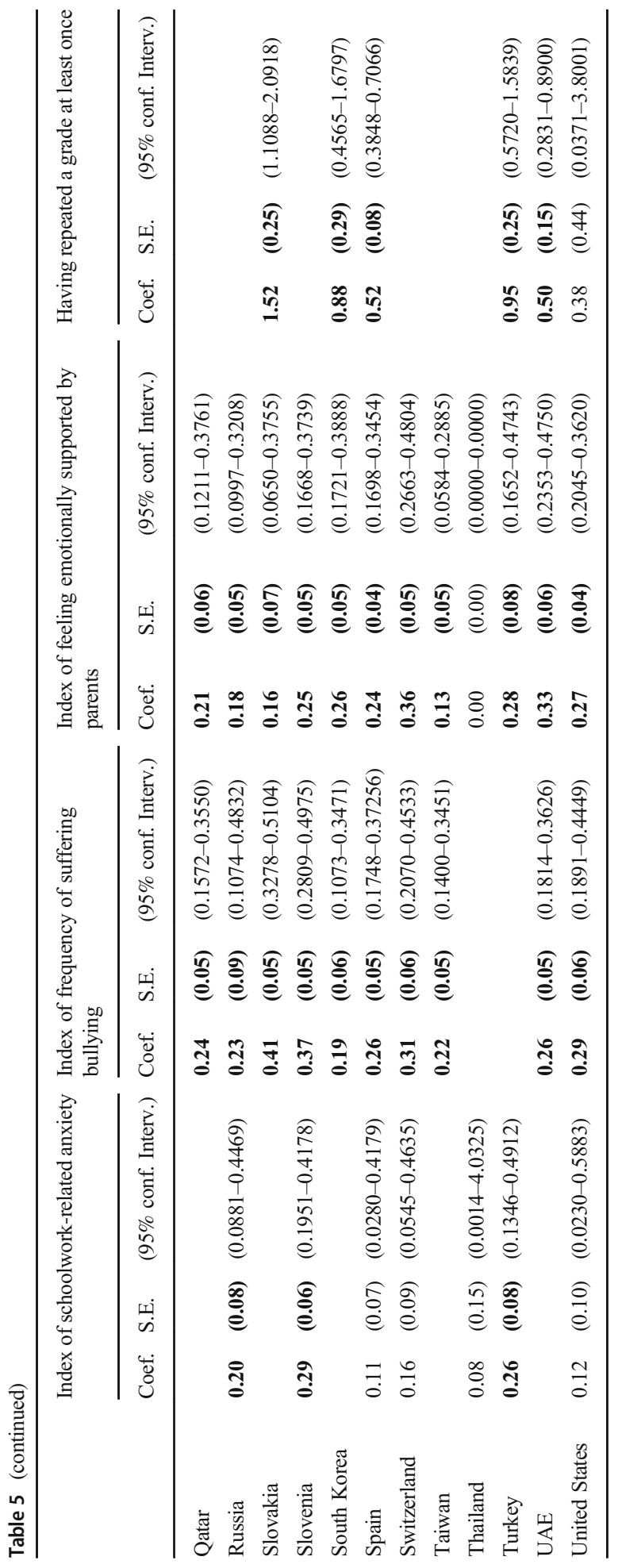


Latvia, Poland and Slovakia go, respectively, from 45.98, 42.41\%, 31.22\%, $24.43 \%$ and $40.40 \%$ to $6.27 \%, 7.04 \%, 7.30 \%, 4.27 \%$ and $6.50 \%$.

\section{Discussion}

\subsection{Main Findings}

We found evidence in support of the three hypotheses that we examined. This is that (1) there is an association between education policy-relevant dimensions of students' lives and their LS; that (2) schools play an important role in shaping students' LS; and that (3) differences across societies regarding the links between education policy and students' LS are significant.

\subsubsection{The Association between Education Policy-Relevant Factors and Students' Life Satisfaction}

In relation to the association between education policy-relevant factors and students' LS, multiple associations were found. In particular, schoolwork-related anxiety (-), the frequency of suffering bullying (-) and feeling emotionally supported by parents in relation to school (+) were revealed as almost universal predictors of students' LS. As to the frequency of suffering bullying, however, a statistically significant effect was not found in South Korea. This may have to do with the fact that among the 53 countries with available data in PISA2015, South Korean students report by far the lowest frequency of feeling bullied (OECD 2017a). Using data from Children's Worlds, Rees and Main (2015) also find that children aged 10 and 12 in South Korea feel bullied less frequently. Regarding schoolwork-related anxiety, despite some exceptions (especially Colombia, France and Chile), this seems to be more important to students' LS than the experience of bullying. This is especially the case of South Korea and Iceland, which are the two countries where the effect of schoolwork-related anxiety in students' LS is by far the greatest. However, by a considerable margin, the greatest effect tends to be observed in relation to feeling emotionally supported by parents in relation to school. Some notable exceptions are Mexico and Chile -where the effect of feeling emotionally supported by parents in relation to school and schoolwork-related anxiety are similar and smaller than the effect of bullying, especially in Chile- and Ireland and Iceland -where the effect of feeling emotionally supported by parents in relation to school is similar to the effect of the experience of bullying and, especially in the case of Iceland, smaller than the effect of schoolwork-related anxiety. Overall, these country differences in the relative importance that distinct factors have in the making of students' LS indicate that the association between education policy and students' LS is complex.

Furthermore, being a girl (-), feeling unfairly treated by teachers $(-)$, valuing cooperation $(+)$, having breakfast before going to school $(+)$, doing vigorous exercise outside school (+), academic competence $(-)$ and talking to parents before and/or after school (+) are associated with students' LS in most countries. Once again, by a considerable margin, the greatest effect size tends to be found in the domain of family relationships (talking to parents). The somewhat surprising negative association 
between academic competence and students' LS contradicts findings from previous research exploring this association. In a meta-analysis exploring the association between academic achievement and SWB, Bücker et al. (2018) find a small to medium positive correlation but also acknowledge that high achieving students do not necessarily report high SWB and that low-achieving students do not automatically report lower SWB.

In addition, in around half of the countries studied, an association was found with regard to SES (positive in all of them but in Slovenia), sense of belonging at school (+), truancy (-) and school type -in this case, when compared with public schools, students' LS is higher in semi-private and/or private schools in some countries and lower in others.

For the remaining predictor variables, the picture is less clear. In a few cases, the effect is positive in some societies and negative in others. Overall, for these remaining predictor variables, an effect is usually found in a smaller number of societies and the effect size tends to be smaller. However, there are some predictor variables that are associated with students' LS in a small number of countries but which are particularly important in these societies. For instance, this is the case for the shortage of educational resources, where a small but statistically significant effect is found only in Spain $\left(-0.15^{* * *}\right)$; and for the percentage of certified teachers in the school, where an effect -rather great in size- is only found in Greece and South Korea $\left(0.36^{*}\right.$ and $0.73^{* * *}$, respectively).

The models that we examined explain, approximately, between one-fifth and one-third of the variation in students' LS. Most of this variation is explained by education policy-relevant factors, especially by self-reported well-being variables. However, both the total proportion of variation in LS explained by these variables and the different contribution to the making of LS of these groups of variables differs substantially by country.

Overall, all this evidence of cross-society differences in the association between education-policy relevant aspects and students' LS suggests that although there are some domains of children's lives that seem to be important to SWB almost universally, in many instances, what is observed in one particular society is not necessarily observed in others. This highlights the importance of comparative research on children's SWB and the necessity of identifying cross-society differences and commonalities in terms of what contributes to children's SWB.

\subsubsection{How Schools May Influence Students' Life Satisfaction}

We also found evidence that schools may play an important role in shaping students' LS. First, there is evidence of school effects in students' LS in all countries but two (Finland and Greece). Second, part of the variation in students' LS is explained by differences between schools. In view of the analysis of the VPC, in the full multilevel model (model 2), this proportion is above $5 \%$ in 24 countries, being particularly great in 5 Eastern European countries: Czech Republic (45.98\%), Estonia (42.41\%), Slovakia $(40.49 \%)$, Latvia $(35.58 \%)$ and Poland $(24.43 \%)$. These results are in line with previous research (see Clair (2014) for the cases of England and the United States) which indicate that, in some societies, schools may explain a large proportion of variation in students' SWB. And third, the association between education policyrelevant factors and students' LS tends to vary by school. That is, there is evidence of school random effects in all societies but Luxembourg and Thailand, meaning that 
school responses to student experiences and characteristics are important. This is particularly important in those Eastern European societies with very high levels of between-school variance in students' LS (Czech Republic, Estonia, Slovakia, Latvia and Poland) as this between-school variance is mostly explained by how schools in these countries treat students who have repeated a grade -which, in these countries, represent around $4-6 \%$. This is an intriguing finding and an interesting point to explore in future studies.

Overall, these results indicate that although schools seem to influence students' LS in all countries, there are important cross-society differences. Not only do schools seem to play a much more important role in some societies than in others but there is also substantial cross-society variation in how they shape students' LS (i.e. through differences when it comes to dealing with bullying, grade repetition, etc.; and perhaps through the way in which students of different characteristics are concentrated in different types of schools, study programmes and/or classrooms). Again, this highlights the important role of comparative research and the need for identifying cross-society differences and commonalities in how schools may influence students' LS and what may explain this.

\subsubsection{The Complex Association between Education Policy and Students' Life Satisfaction}

Although this study did not provide evidence of causal mechanisms, the finding that multiple education policy-amenable factors are associated with students' LS suggests that there is room for education policy to influence children's SWB. Education policyrelevant factors - and, particularly, self-reported well-being - seem to explain a significant proportion of the variation in students' LS. Furthermore, these findings support the position that both schools and education policy interventions at the school level may promote SWB. However, an important conclusion is that the association between education policy and children's SWB is complex. Many associations vary by school and across societies. For those interested in if and how schools may promote children's SWB, a promising way forward could involve conducting comparative research on children's SWB adopting a more nuanced approach to study this complexity, with consideration of school-level characteristics and cross-society differences but also factors at other levels (child, home, community) of the child's environment, and the interconnections between them.

\subsection{Implications for Education Policy and Practice}

In terms of implications for education policy and practice, some lessons are particularly important in relation to specific policies and policy domains. First, tackling bullying and school anxiety is essential to increase children's SWB. Second, interactions with parents are also very important. Although these may not seem as amenable by policy as bullying and school anxiety, practitioners and policymakers can -and should- work towards facilitating parental engagement with school and supporting parents in their efforts to provide a supportive and nurturing environment. Third, the quality of the relationships between students and teachers is important and measures intended to improve this -and particularly, to reduce the feeling of being unfairly treated by teachers- could boost child SWB. Fourth, the promotion of healthy habits -having 
breakfast before going to school and practising vigorous exercise several days a weekis another way in which children's SWB could be increased in many countries. Fifth, schools and education systems that tackle truancy, promote values of cooperation and manage to increase the sense of belonging to school among students may help in achieving higher levels of SWB.

Furthermore, attention needs to be paid to country-specific issues -this is factors which, regardless of the number of countries were effects were found, may be of especial importance in a specific society. For example, in view of the results observed for Spain, increasing the availability of human and material resources in schools in this nation could result in higher SWB. The fact that some interventions are likely to be important in some countries but not in others highlights the importance of policymakers having access to nationally representative data -and, ideally, also that of regions/states and municipalities. This would enable a more effective identification of which policy and practice interventions are more likely to increase the SWB of their children.

It is also important to note that, although the focus of this research was on education policy, for some of these factors (e.g. interactions with parents, health habits, etc.) interventions would not be limited to schools and education policy but would also involve taking action in other policy domains (health, work-life balance, broader social policy, etc.).

In relation to the role of schools, evidence that individual schools -and not only education systems- may have the capacity to influence students' SWB has policy implications. The fact that students' LS differs from one school to another may lead to two hypotheses, which are non-mutually exclusive and policy-relevant. The first one is that schools are different enough in ways which are important to students' LS. And the second one is that students of certain characteristics are more likely to attend some schools than others. In view of the first of these two hypotheses, policymakers should aim at identifying the characteristics that result in higher LS in some schools and how these conditions can be promoted in others through changes in policy and practice. In view of the results presented in this research, some of these conditions are to do with school anxiety, bullying, feeling emotionally supported by parents and grade repetition, whose impact on students' LS varies across schools in many countries. Some schools do better than others when it comes to dealing with these issues, and we should aim to identify how schools which do worse can learn from those which do better. And in view of the second hypothesis, policymakers should consider the effects on child SWB -and not only academic outcomes- of policies which determine how students are distributed into schools (e.g. school admission policies).

\subsection{Limitations}

Some important limitations of this study should be noted. Firstly, the data used includes only one outcome variable: LS. Ideally, other domains of SWB -both cognitive and affectiveand eudaimonic well-being would be considered. Moreover, LS data are often negatively skewed, which might affect the validity of the results. We do not make use of any technique to deal with this issue and, although there is disagreement among academics on how one has to account for the special character of SWB variables (see Ferrer-i-Carbonell and Frijters 2004), working with skewed data might affect the validity of the results. In addition, this research is limited to 15-16-year-old adolescents who are enrolled in mainstream education, mainly in high-income countries. This is a rather restrictive sample but represents the best 
data currently available to explore this issue. Given the nature of the data and the research design used, this thesis did not provide evidence of causal mechanisms. This was beyond the scope of this research mainly due to data availability limitations (i.e. the lack of longitudinal data). Nonetheless, these multilevel models controlled for a large number of possible confounding influences and, overall, evidence on the existence of an association between education policy and students' LS is quite robust. However, caution is needed when interpreting results as the findings indicate only an association - not the direction which that association might take. Additionally, self-reported well-being is not independent of LS, which may be why it explains most of the variation in LS. Therefore, further investigations into the comparative roles of self-reported well-being variables compared to other factors is indicated. Moreover, some of the factors studied are not policy-relevant (see section 2.2 for a rationale for their inclusion in the models), which must be kept in mind when assessing the links between education policy and students' LS investigated in this paper. Finally, as explained in section 2.3, we adopted a rather conservative approach to dealing with missing data, excluding from the analysis multiple countries and variables of interest. However, for some independent variables in some countries levels of missing data are above $20 \%$, which may pose another limitation to this research. The aim of this paper was to provide a broad overview of this topic across a range of countries - and it would be useful to follow this up with studies focusing in more depth on individual countries, in which missing data should be handled differently to ensure that sufficient cases are available for the analyses performed.

\section{Conclusions}

There is an association between multiple education policy-relevant dimensions and students' LS, and schools play an important role in shaping students' LS. These findings suggest that there is room for education policy to impact children's SWB in different ways. The association between education policy and students' LS varies substantially across schools and societies. This suggests that this association is complex and that adopting a more nuanced approach to study the links between different aspects of the child's ecology and their impact on children's SWB may further our understanding of whether and how societies can make children happier.

\section{Appendix 1. Variables information}

This appendix provides more detailed information about the variables used in this study. In particular, information is provided regarding the PISA 2015 items associated with each of the indices that we used (Table 6) and the transformations performed on the original PISA 2015 variables (Table 7).

\section{Dependent variable: students' LS}

Students' LS is the only outcome variable considered in this study. We used the original PISA 2015 variable. In PISA 2015, LS was assessed using Cantril's ladder (Cantril 1966), asking students to rate how satisfied they feel about their lives these days from 0 (not at all satisfied) to 10 (completely satisfied). 


\section{Independent variables}

\section{Sociodemographics: socioeconomic status and gender}

Socioeconomic status was assessed using PISA's index of Economic, Social and Cultural Status (ESCS), which is derived based on information of parents' level of education and occupational status and the level of material well-being in the household (see page 339 of PISA's technical report for a more detailed description; OECD $2017 b$ ). The original ESCS index was standardised in PISA 2015 with reference to all participating countries and economies. In this paper, this index was re-standardised 33 times with reference to each country and economy considered in the analysis.

Gender was assessed using the same dichotomous variable (boy, girl) provided in PISA 2015.

\section{Self-reported well-being}

We considered the following five indices: schoolwork-related anxiety, sense of belonging at school, frequency of suffering bullying, feeling unfairly treated by teachers and feeling emotionally supported by parents in relation to school. The original PISA 2015 indices were derived using IRT scaling with information from all the participating countries and economies (see Table 7). In this paper, we focused on within-country differences in 33 of these societies only. For this reason, instead of using the original PISA variable, we created simple-derived indices using information from the corresponding items for each of these variables -i.e. summing up the values assigned to each response in the Likert-scale of each of the items (see Table 6) considered in the index. These simple derived indices were then standardised with reference to each of the 33 countries, with 0 representing the average and 1 the standard deviation (see Table 7).

\section{Time use, health habits and ICT use}

In this paper, we studied a series of measures of students' time use and health habits. These include, first, information on the total learning time of students at school (in minutes per week) and out-of-school study time per week (in hours). We re-standardised the original PISA 2015 indices (see Table 7) with reference to the 33 countries. In addition, we used the information contained in the PISA 2015 items ST076 and ST078. These ask, respectively, whether the student did the following tasks in the previous day before or after school: study for school or homework, watch TV/DVD/Video, read a book/newspaper/magazine, use internet/chat/social networks, play videogames, meet friends or talk to friends on the phone, talk to your parents, work in the household or take care of other family members, work for pay, exercise or practice a sport, eat breakfast (before school) and eat dinner (after school). All these items were considered time use aspects and/or health habits. For all of them, we created a variable with three categories: did not do it, did it before or after school, and did it before and after school. The only exceptions are having breakfast and having dinner, which remain as two separate dichotomous variables (see Table 7). Another measure of health habits we examined in this paper is the number of days the student practised vigorous exercise outside the school in the past week. In this case, we used the original PISA variable (see Table 7). 
Table 6 Indices and corresponding PISA 2015 items

\begin{tabular}{cc}
\hline Index & Associated \\
PISA index & PISed items Items
\end{tabular}

\begin{tabular}{ccc}
\hline $\begin{array}{c}\text { Index of schoolwork-related anxi- } \\
\text { ety }\end{array}$ & ANXTEST & $\begin{array}{c}\text { ST118 } \\
\text { To what extent do you disagree or agree with the } \\
\text { following statements about yourself? } \\
\text { (Strongly disagree; Disagree; Agree; Strongly } \\
\text { agree) }\end{array}$
\end{tabular}

Index of sense of belonging at BELONG school

Index of frequency of suffering beingbullied bullying

Index of feeling unfairly treated by teachers
ST118Q01NA I often worry that it will be difficult for me taking a test.

ST118Q02NA I worry that I will get poor $<$ grades $>$ at school.

ST118Q03NA Even if I am well-prepared for a test I feel very anxious.

ST118Q04NA I get very tense when I study for a test.

ST118Q05NA I get nervous when I don't know how to solve a task at school.

ST034 Thinking about your school: to what extent do you agree with the following statement?

(Strongly disagree; Disagree; Agree; Strongly agree)

ST034Q01TA I feel like an outsider (or left out of things) at school.

ST034Q02TA I make friends easily at school.

ST034Q03TA I feel like I belong at school.

ST034Q04TA I feel awkward and out of place in my school.

ST034Q05TA Other students seem to like me.

ST034Q06TA I feel lonely at school.

ST038 During the past 12 months, how often have you had the following experiences in school?

(Never or almost never; A few times a year; A few times a month; Oncea week or more)

ST038Q01NA*

ST038Q02NA*

ST038Q03NA Other students left me out of things on purpose.

ST038Q04NA Other students made fun of me.

ST038Q05NA I was threatened by other students.

ST038Q06NA Other students took away or destroyed things that belonged to me.

ST038Q07NA I got hit or pushed around by other students.

ST038Q08NA Other students spread nasty rumours about me.

ST039 During the past 12 months, how often did you have the following experiences at school?

(Never or almost never; A few times a year; A few times amonth; Once a week or more)

ST039Q01NA Teachers called on me less often than they called on other students.

ST039Q02NA Teachers graded me harder than they graded other students.

ST039Q03NA Teachers gave me the impression that they think I am less smart than I really am.

ST039Q04NA Teachers disciplined me more harshly than other students.

ST039Q05NA Teachers ridiculed me in front of others. 
Table 6 (continued)

Index Associated
PISA index used items Items
PISA

\begin{tabular}{|c|c|c|c|}
\hline & & ST039Q06NA & $\begin{array}{l}\text { Teachers said something insulting to me in front of } \\
\text { others. }\end{array}$ \\
\hline \multirow[t]{6}{*}{$\begin{array}{l}\text { Index of feeling emotionally } \\
\text { supported by parents in relation } \\
\text { to school }\end{array}$} & EMOSUPS & ST123 & $\begin{array}{l}\text { Thinking about }<\text { the last academic year }>\text {, to what } \\
\text { extent do you agree with the following } \\
\text { statements? }\end{array}$ \\
\hline & & & $\begin{array}{l}\text { (Strongly disagree; Disagree; Agree; Strongly } \\
\text { agree) }\end{array}$ \\
\hline & & ST123Q01NA & My parents are interested in my school activities. \\
\hline & & ST123Q02NA & $\begin{array}{l}\text { My parents support my educational efforts and } \\
\text { achievements. }\end{array}$ \\
\hline & & ST123Q03NA & $\begin{array}{l}\text { My parents support me when I am facing } \\
\text { difficulties at school. }\end{array}$ \\
\hline & & ST123Q04NA & My parents encourage me to be confident. \\
\hline \multirow[t]{10}{*}{$\begin{array}{l}\text { Index of time spent using ICT at } \\
\text { school in general }\end{array}$} & USESCH & $\mathrm{IC} 011$ & $\begin{array}{l}\text { Frequency of use at school: } \\
\text { (Never or hardly ever; Once or twice a month; } \\
\text { Once or twice a week; Almost every day; Every } \\
\text { day) }\end{array}$ \\
\hline & & IC011Q01TA & $<$ Chatting on line $>$ at school. \\
\hline & & IC011Q02TA & Using email at school. \\
\hline & & IC011Q03TA & Browsing the Internet for schoolwork. \\
\hline & & IC011Q04TA & $\begin{array}{l}\text { Download } \backslash \text { upload } \backslash \text { browse schools web (e.g. } \\
\quad<\text { intranet }>\text { ). }\end{array}$ \\
\hline & & IC011Q05TA & Posting my work on the schools website. \\
\hline & & IC011Q06TA & Playing simulations at school. \\
\hline & & IC011Q07TA & $\begin{array}{l}\text { Practicing and drilling, foreign language learning or } \\
\text { math. }\end{array}$ \\
\hline & & IC011Q08TA & Doing homework on a school computer. \\
\hline & & IC011Q09TA & $\begin{array}{l}\text { Using school computers for group work and } \\
\text { communication with other students. }\end{array}$ \\
\hline \multirow[t]{10}{*}{$\begin{array}{l}\text { Index of time spent using ICT } \\
\text { outside school for schoolwork }\end{array}$} & HOMESCH & $\mathrm{IC} 010$ & $\begin{array}{l}\text { Frequency of use outside of school: } \\
\text { (Never or hardly ever; Once or twice a month; } \\
\text { Once or twice a week; Almost every day; Every } \\
\text { day) }\end{array}$ \\
\hline & & IC010Q01TA & $\begin{array}{l}\text { Browsing the Internet for schoolwork (e.g. for } \\
\text { preparing an essay or presentation }\end{array}$ \\
\hline & & IC010Q02NA & $\begin{array}{l}\text { Browsing the Internet to follow up lessons, e.g. for } \\
\text { finding explanations. }\end{array}$ \\
\hline & & IC010Q03TA & $\begin{array}{l}\text { Using email for communication with other students } \\
\text { about schoolwork. }\end{array}$ \\
\hline & & IC010Q04TA & $\begin{array}{l}\text { Using email for communication with teacher } \\
\text { submit of homework or other schoolwork }\end{array}$ \\
\hline & & IC010Q05NA & $\begin{array}{l}\text { Using Social Networks for communication with } \\
\text { other students about schoolwork. }\end{array}$ \\
\hline & & IC010Q06NA & $\begin{array}{l}\text { Using Social Networks for communication with } \\
\text { teachers. }\end{array}$ \\
\hline & & IC010Q07TA & $\begin{array}{l}\text { Download } \backslash \text { upload } \backslash \text { browsing from school website } \\
\text { (e.g. time table or course materials }\end{array}$ \\
\hline & & IC010Q08TA & $\begin{array}{l}\text { Checking the schools website for announcements, } \\
\text { e.g. absence of teachers. }\end{array}$ \\
\hline & & IC010Q09NA & Doing homework on a computer. \\
\hline
\end{tabular}


Table 6 (continued)

\begin{tabular}{|c|c|c|c|}
\hline Index & $\begin{array}{l}\text { Associated } \\
\text { PISA index }\end{array}$ & $\begin{array}{l}\text { PISA items } \\
\text { used }\end{array}$ & Items \\
\hline
\end{tabular}

Index of time spent using ICT at home for leisure

Index of valuing cooperation

Index of truancy

Index of shortage of material and human school resources
IC010Q10NA Doing homework on a mobile device.

IC010Q11NA Downloading learning apps on a mobile device.

IC010Q12NA Downloading science learning apps on a mobile device.

ENTUSE IC008 Frequency of use of digital devices outside school for:

(Never or hardly ever; Once or twice a month; Once or twice a week; Almost every day; Every day)

IC008Q01TA Playing one-player games.

IC008Q02TA Playing collaborative online games.

IC008Q03TA Using email.

IC008Q04TA < Chatting online $>$ (e.g. $<$ MSN $®>)$.

IC008Q05TA Social networks (e.g. $<$ Facebook $>$, $<$ MySpace $>$ ).

IC008Q07NA Online games $\backslash$ Social Networks (e.g. $<$ Farmville ${ }^{\circledR}>$, $<$ The Sims Social $>$ ).

IC008Q08TA Browsing the Internet for fun videos, e.g. $<$ YouTube $>$ ).

IC008Q09TA Reading news on the Internet (e.g. current affairs).

IC008Q10TA Obtaining practical information from the Internet

IC008Q11TA Downloading music, films, games or software from the Internet.

IC008Q12TA Uploading your own created contents for sharing

IC008Q13NA Downloading new apps on a mobile device.

CPSVALUE ST082 To what extent do you disagree or agree with the following statements about yourself?

(Strongly disagree; Disagree; Agree; Strongly agree)

ST082Q02NA To what extent do you disagree or agree about yourself? I am a good listener.

ST082Q03NA I enjoy seeing my classmates be successful.

ST082Q08NA I take into account what others are interested in.

ST082Q12NA I enjoy considering different perspectives.

ST062 In the last two full weeks of school, how often:

(None; One or two times; Three or four times; Five times or more)

ST062Q01TA I $<$ skipped $>$ a whole school day

ST062Q02TA I $<$ skipped $>$ some classes

ST062Q03TA I arrived late for school

EDUSHORT;

STAFFSHORT

SC017 Is your school's capacity to provide instruction hindered by any of the following issues?

(Not at all; Very little; To some extent; A lot)

SC017Q05NA Lack of educational material (e.g. textbooks, IT equipment, library or lab material).

SC017Q06NA Inadequate or poor quality educational material (e.g. textbooks, IT equipment).

SC017Q07NA Lack of physical infrastructure (building, grounds, heating /cooling, lighting). 
Table 6 (continued)

\begin{tabular}{|c|c|c|c|}
\hline Index & $\begin{array}{l}\text { Associated } \\
\text { PISA index }\end{array}$ & $\begin{array}{l}\text { PISA items } \\
\text { used }\end{array}$ & Items \\
\hline & & SC017Q08NA & $\begin{array}{l}\text { Inadequatelpoor quality phys infrastructure } \\
\text { (building, grounds, heating } \backslash \text { cooling). }\end{array}$ \\
\hline & & SC017Q01NA & A lack of teaching staff. \\
\hline & & SC017Q02NA & Inadequate or poorly qualified teaching staff. \\
\hline & & SC017Q03NA & A lack of assisting staff. \\
\hline SC017Q04NA & $\begin{array}{l}\text { Inadequate or } \\
\text { poorly } \\
\text { qualified } \\
\text { assisting } \\
\text { staff. }\end{array}$ & & \\
\hline \multirow[t]{7}{*}{$\begin{array}{l}\text { Index of teachers' behaviour } \\
\text { hindering teaching }\end{array}$} & TEACHBEHA & SC061 & $\begin{array}{l}\text { Is your school's capacity to provide instruction } \\
\text { hindered by any of the following issues? }\end{array}$ \\
\hline & & & (Not at all; Very little; To some extent; A lot) \\
\hline & & SC061Q06TA & Teachers not meeting individual students' needs \\
\hline & & SC061Q07TA & Teacher absenteeism \\
\hline & & SC061Q08TA & Staff resisting change \\
\hline & & SC061Q09TA & Teachers being too strict with students \\
\hline & & SC061Q10TA & Teachers not being well prepared for classes \\
\hline
\end{tabular}

Note: Items ST038Q01NA* and ST038Q02NA* were not considered in the PISA 2015 index beingbullied because, in view of results from an exploratory analysis conducted by PISA analysts, they "did not load well onto a unidimensional construct and were also not strongly correlated with the other six items" (see PISA 2015 Technical Report for more details). For the same reasons, these items were not used in the index of frequency of suffering bullying used in this paper neither

We also used three indices of Information and Communication Technologies (ICT) use. This included a measure of time spent using ICT at school in general, a measure of time spent using ICT outside the school for schoolwork, and a measure of time spent using ICT at home for leisure. Using information from the corresponding PISA 2015 items, we derived three standardised measures of ICT in the exact same manner that we derived the self-reported well-being indices (see Table 7).

\section{Other student-level variables}

We used a standardised measure of attitudes towards cooperation which was derived from the same items used in the corresponding PISA index (see Table 6) in the exact same way as in the case of the self-reported well-being variables described above (see Table 7).

The truancy index that we use was derived using information from the three items contained in the corresponding PISA variable (see Table 6). First, we transformed the fourpoint Likert scale into a three-point Likert scale due to the extremely small proportion of responses in the last two categories. Then we derived a simple index and standardised it in the same way as with the self-reported well-being variables (see Table 7).

Based on the information contained in the corresponding PISA variable, we derived a dichotomous measure of whether the student has repeated a grade at least once or not (see Table 7). 
Study programme (general, pre-vocational, vocational, modular) was assessed using the same categorical variable provided in PISA 2015 (see Table 7).

In relation to the number of years a student spent in early childhood education and care, we merged the last four answer categories of the original PISA 2015 variable into one (5 years or more) (see Table 6 ). This is due to the extremely small proportion of responses observed within these last categories.

The measure of academic competence was created by estimating the mean of the 10 plausible values in each domain (reading, maths and science) and then the mean of the three means (an alternative approach might involve using the mean of the first plausible value in each domain). Then we standardised this index with reference to each country (see Table 6). However, it is important to note that, although multiple studies oriented to predict academic competence with PISA data have used the 'raw' plausible values before as a measure of academic competence (e.g. Lavy 2015), this practice is not recommended by some researchers who argue that a version of 'Rubin's rules' for handling multiple imputations should be used (see Jerrim et al. 2017, for a detailed discussion). Details on how to do this are provided in OECD (2009) and in online Appendix D. In this research, academic competence is not studied as an outcome variable but simply as a control variable. For this reason, estimating the means of the plausible values should not compromise the validity of the results obtained in the quantitative analysis to a significant extent.

\section{School-level characteristics}

We used PISA's original variables (see Table 7) regarding the following aspects: population size of the community where the school is located; school type (i.e. private (privately funded, privately run), semi-private (publically funded, privately run) or public (publically funded, publically run); school size in total number of enrolled students in the school; average class size for 15-year-olds in the school, studentteacher ratio; percentage of qualified teachers in the school.

PISA 2015 contains an index of shortage of material resources at school (EDUSHORT) and an index of short of educational staff (STAFFSHORT). We created a simple derived index of shortage of school resources with information from all the items considered in the indices of shortage of material resources at school and shortage of educational staff, which was then standardised as in the self-reported well-being variables (see Tables 6 and 7).

Teachers' behaviour hindering learning was considered by using a standardised measure that was derived from the same items used in the corresponding PISA2015 index (see Table 6) in the same way as in the case of self-reported well-being variables described in this section.

Finally, we used two dichotomous measures of whether the school practices ability grouping in the modal grade for 15-year-old between classes and within classes, which were derived from PISA's variable SC042 (see Table 7).

\section{Appendix 2. Tables}

This appendix includes the tables showing the results - by country - of the direct effects of independent variables at student- and school-level (Tables 8, 9, 10 and 11). 


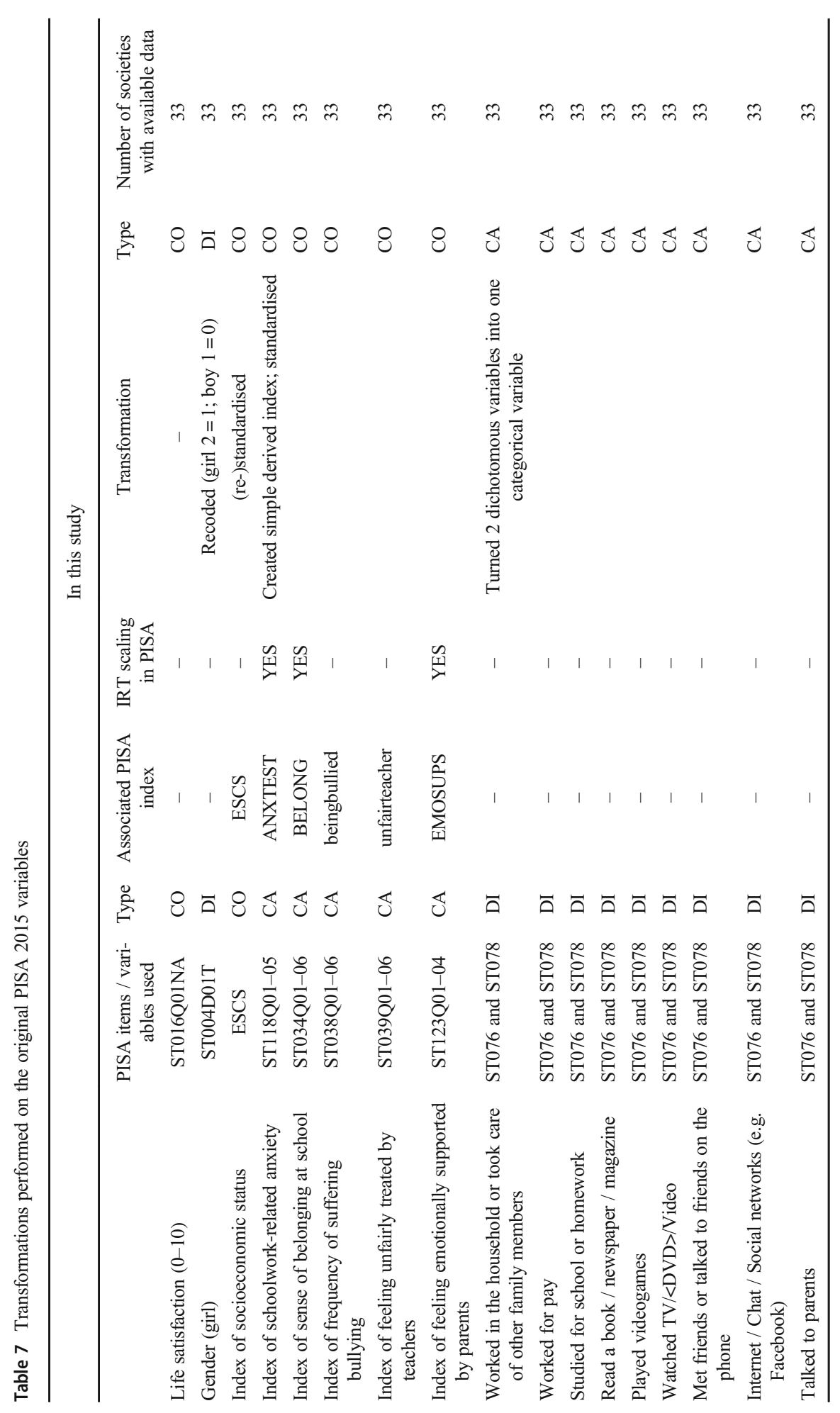




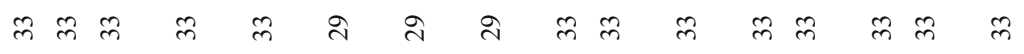

ีี

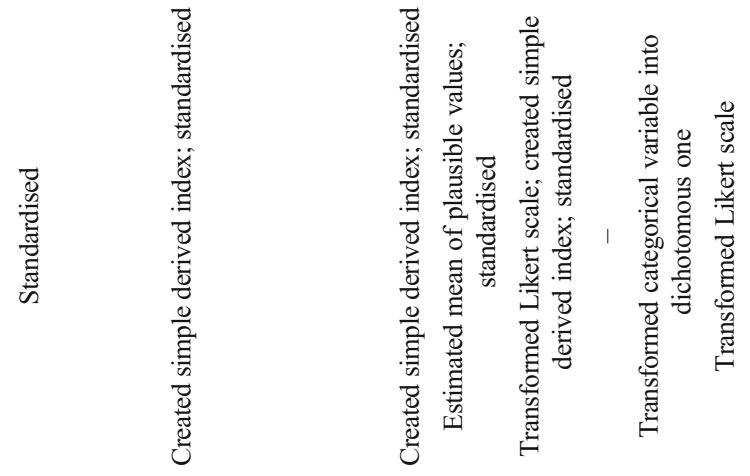

そ

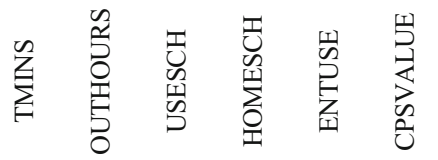

పే冋

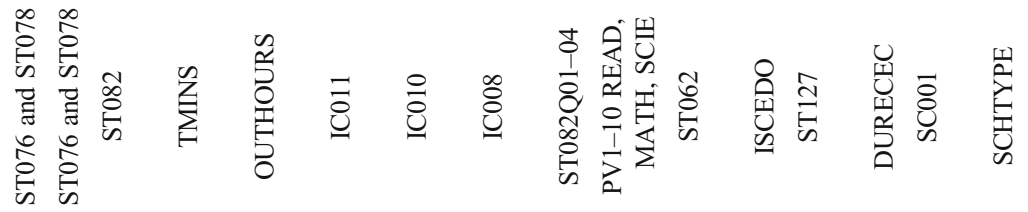

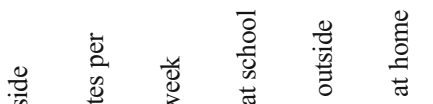

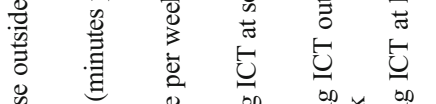

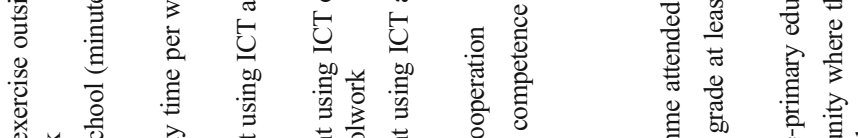

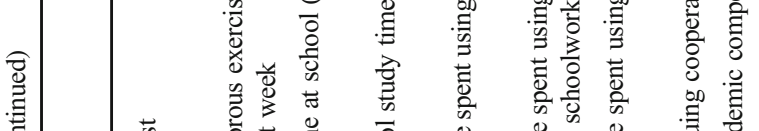

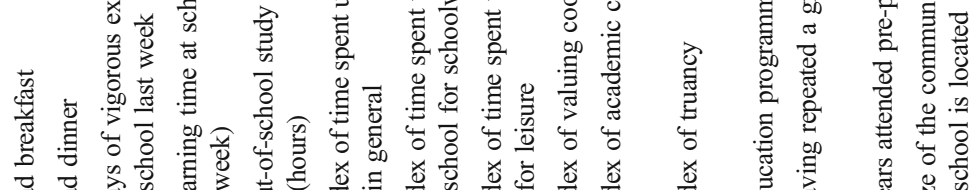




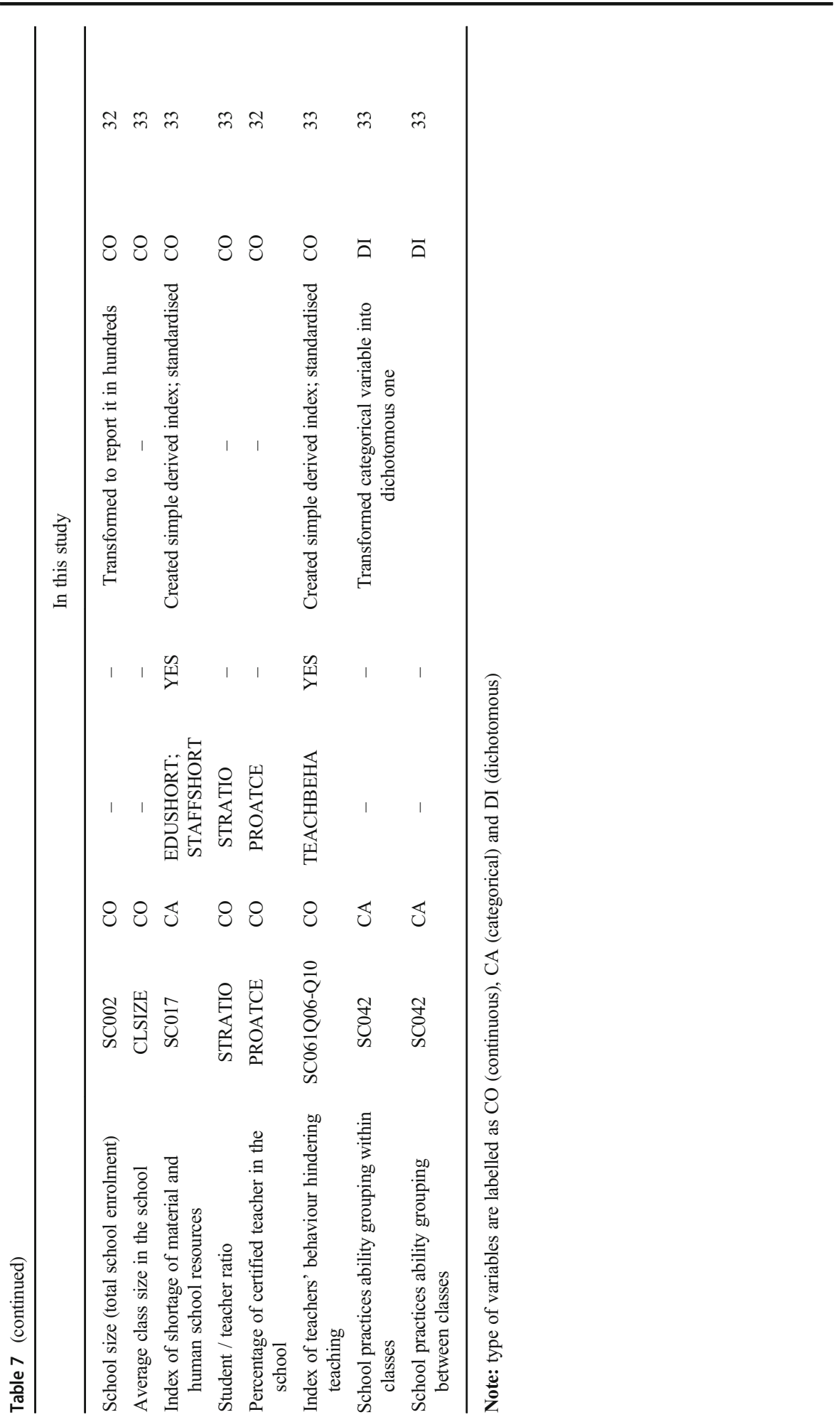




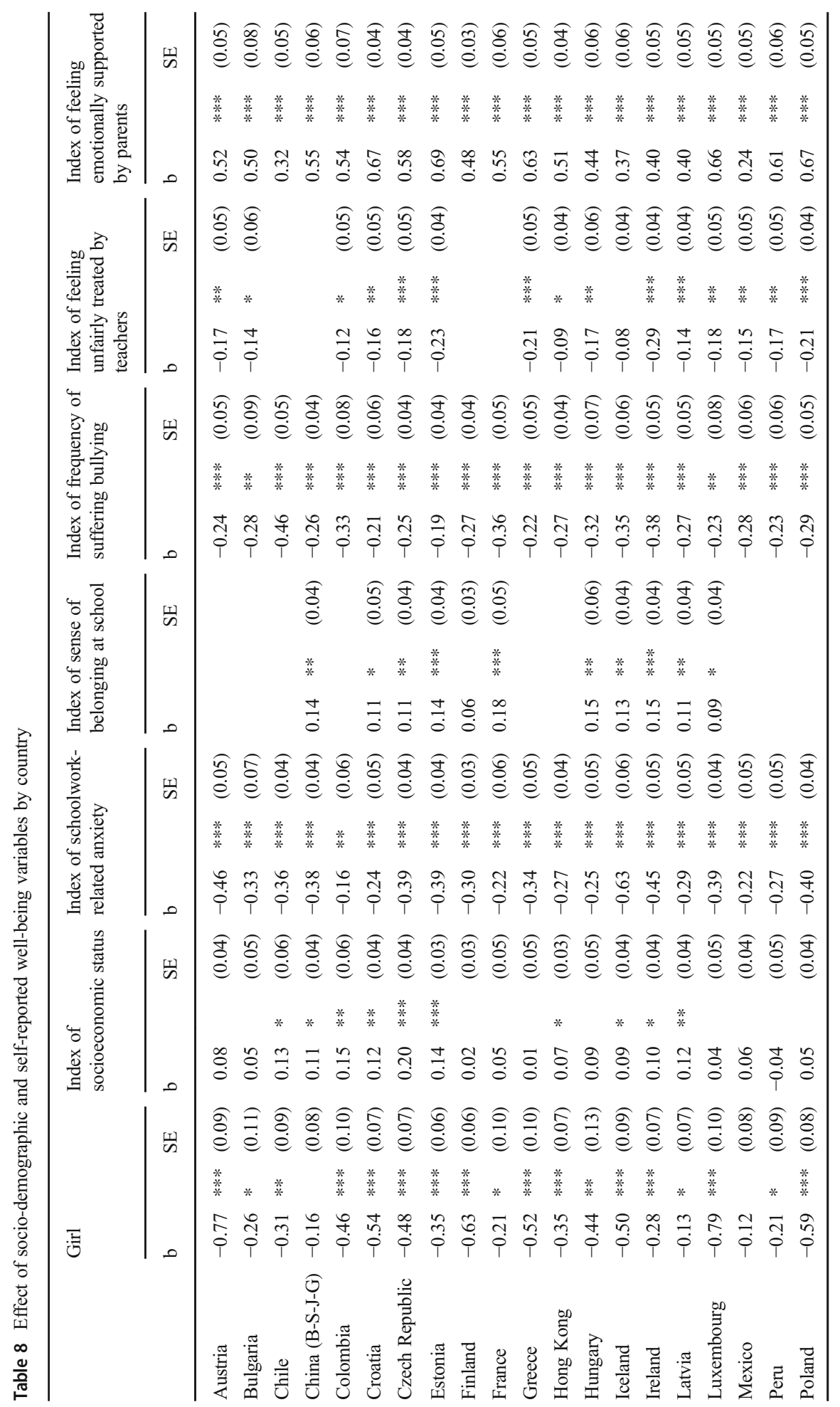




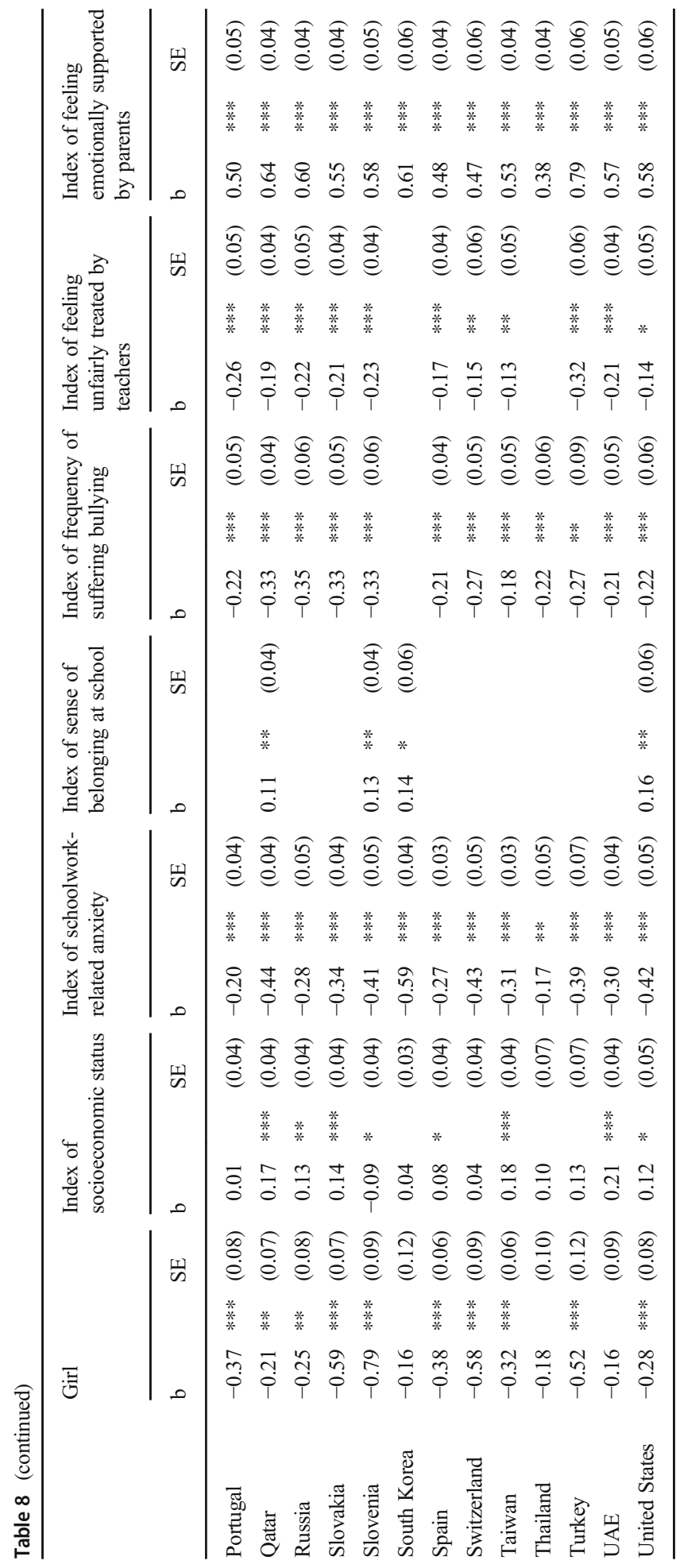




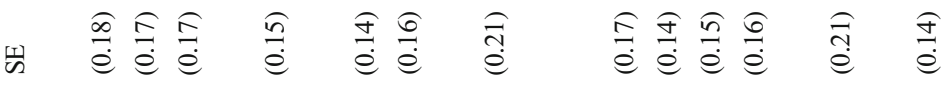

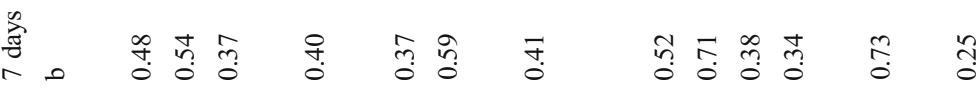

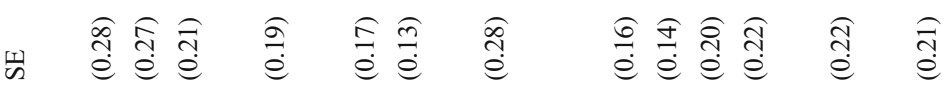

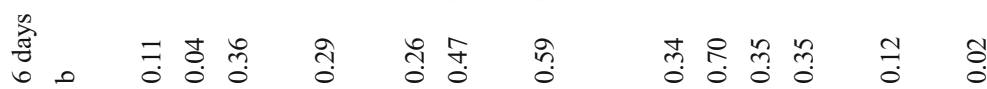

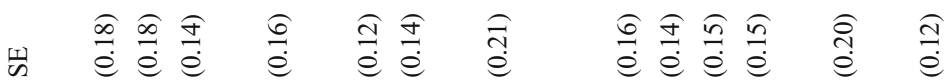

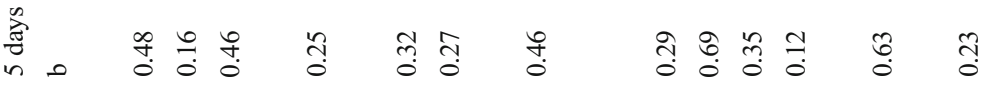

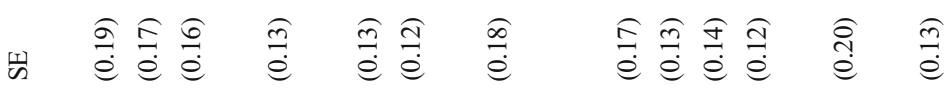

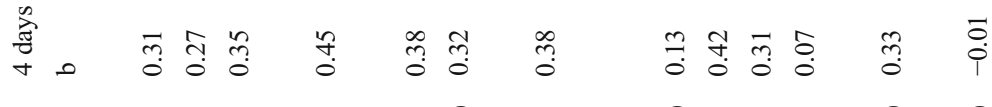

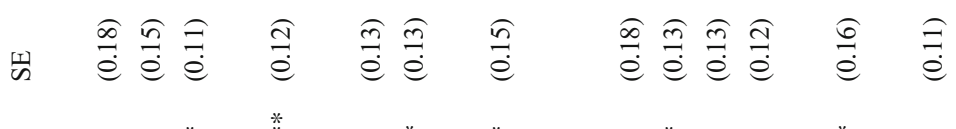

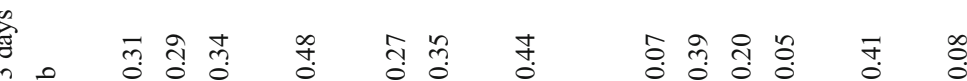

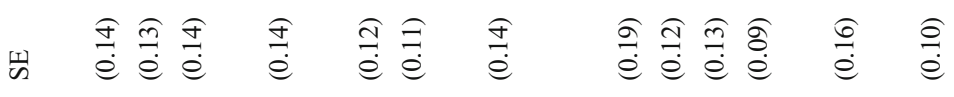

离 


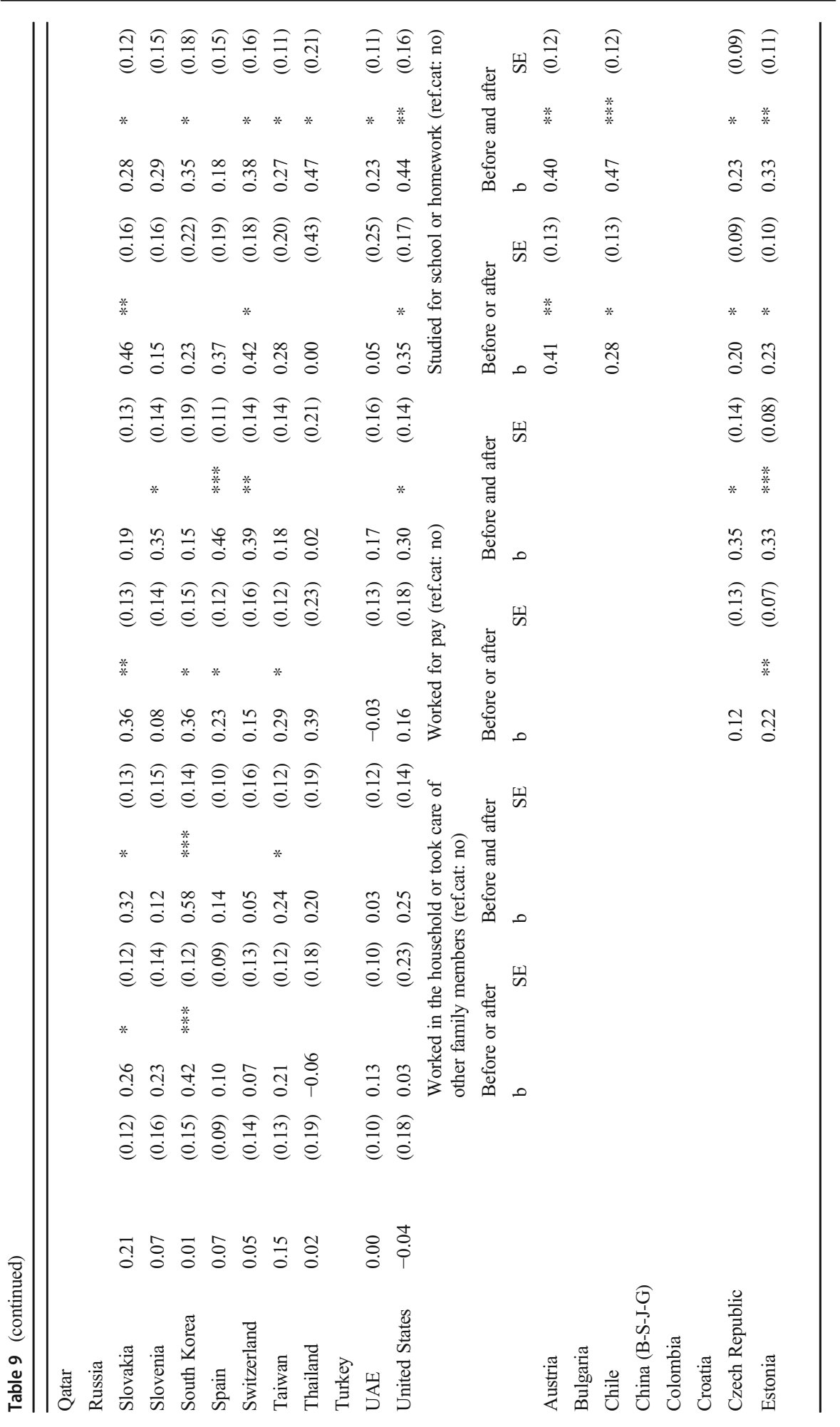




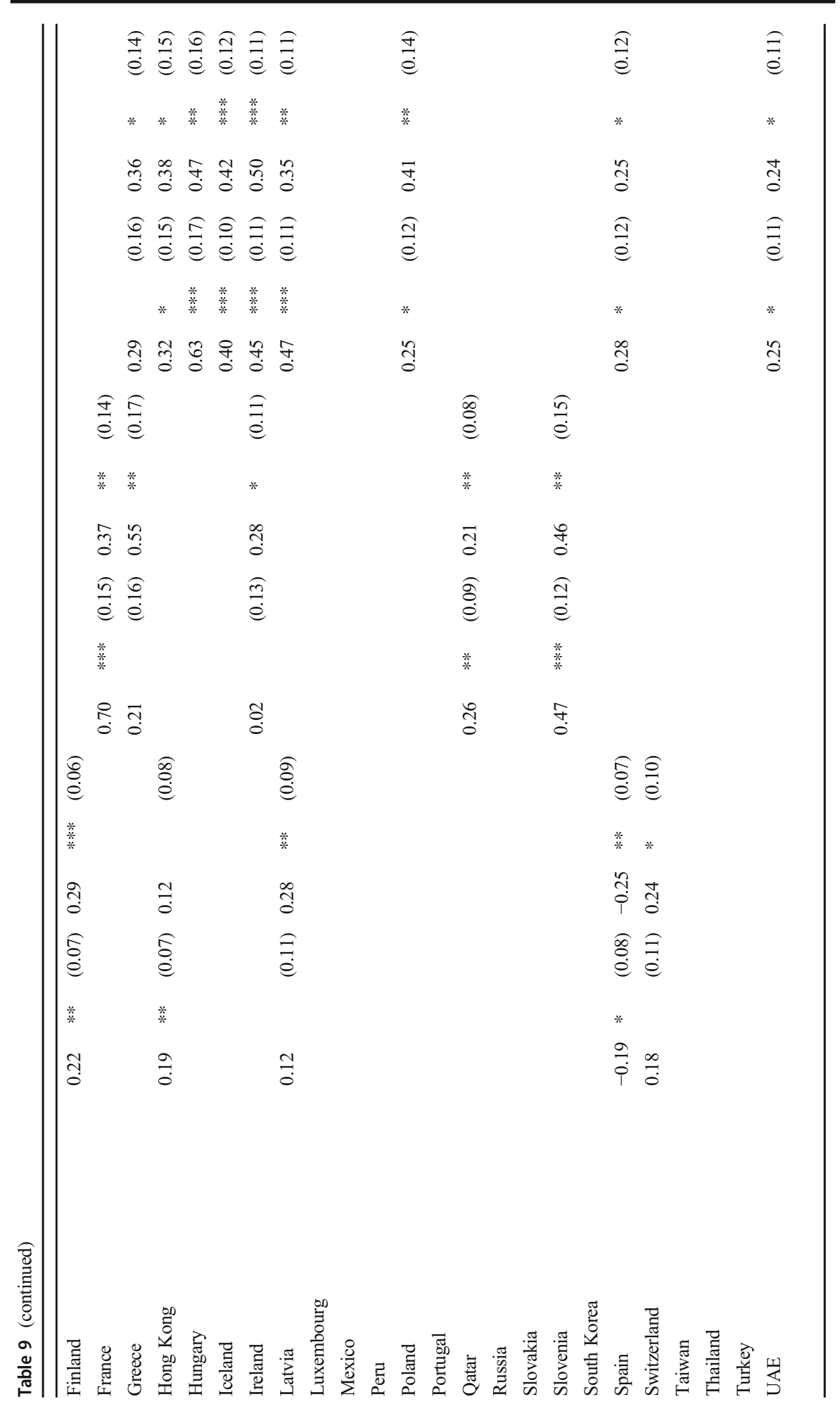




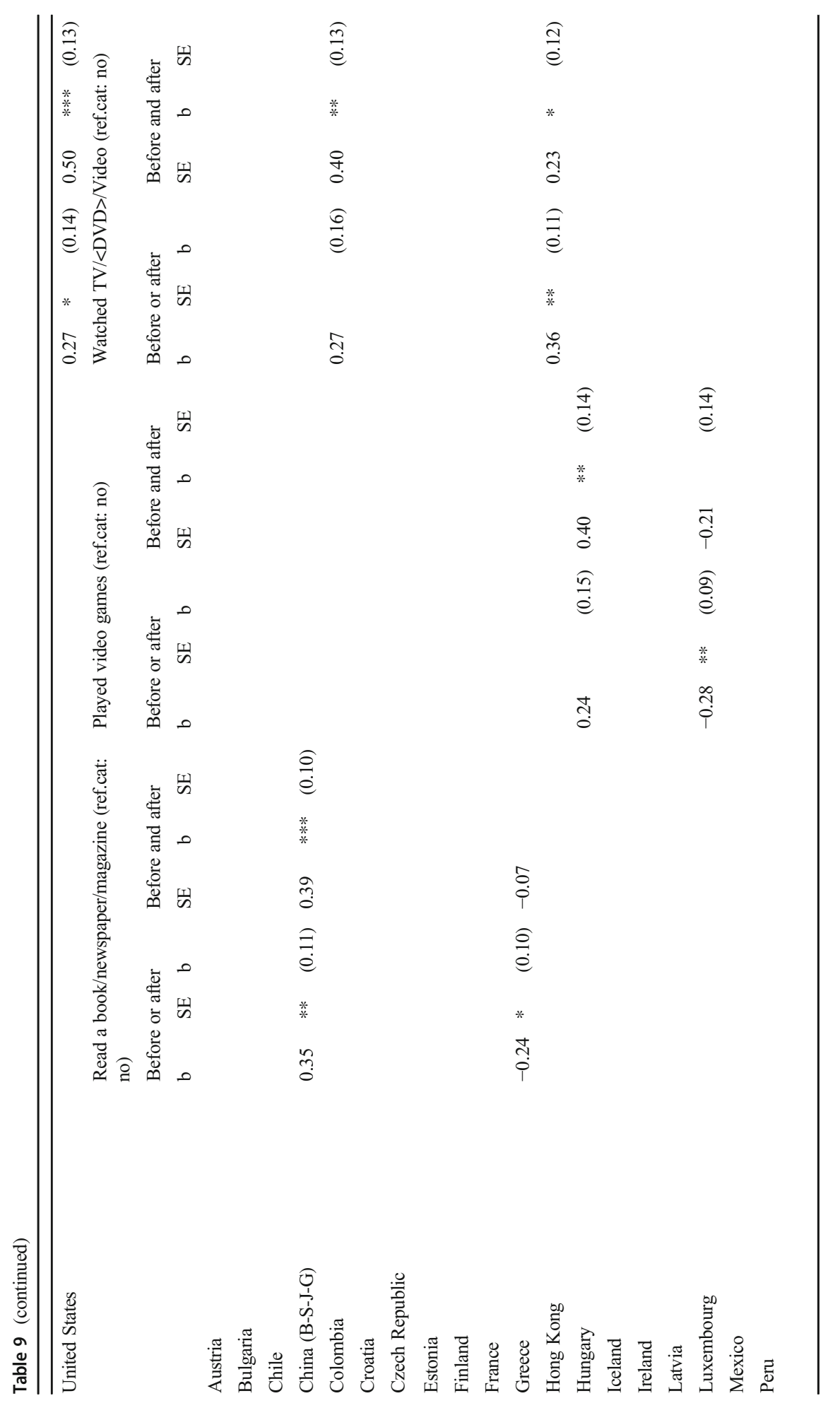




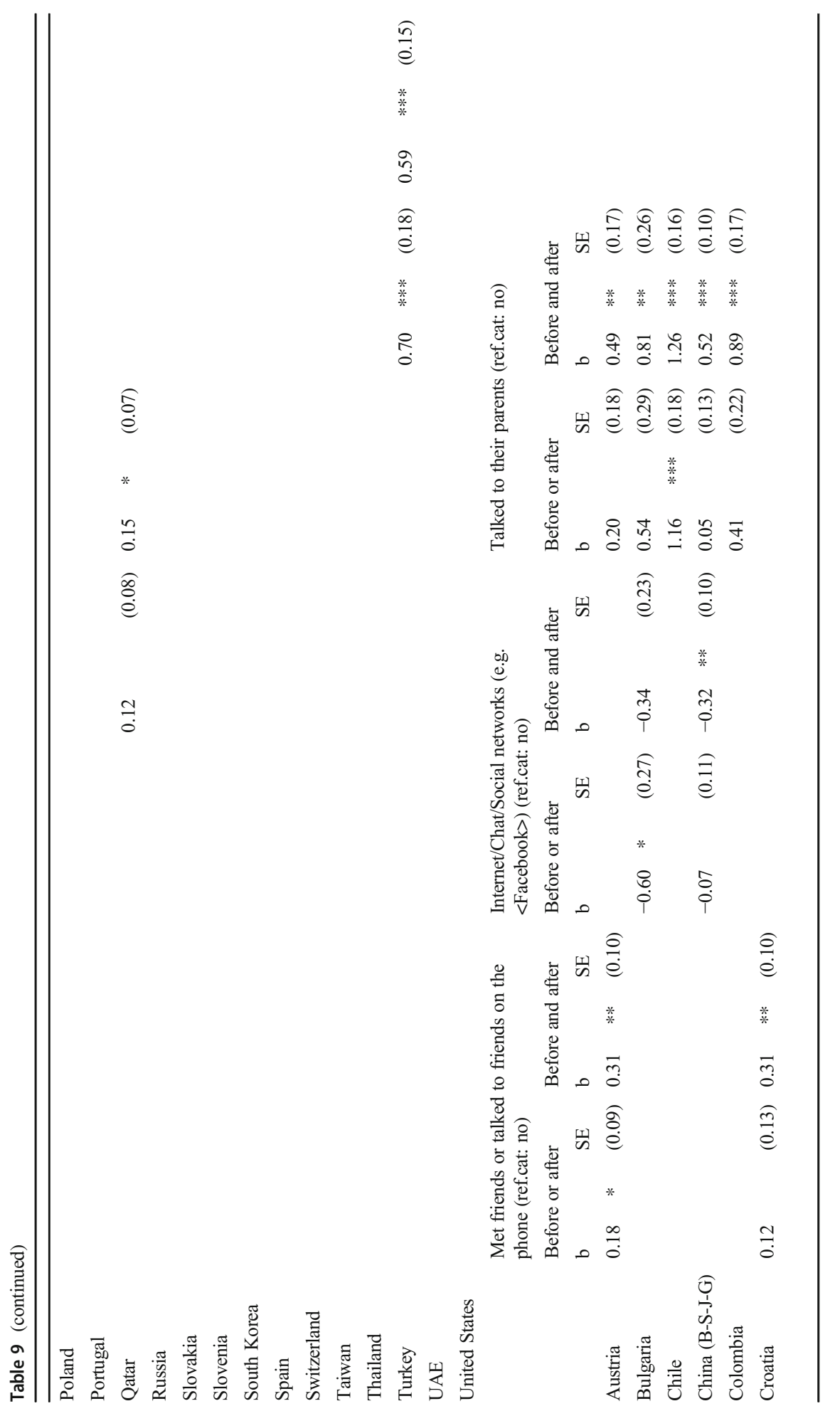




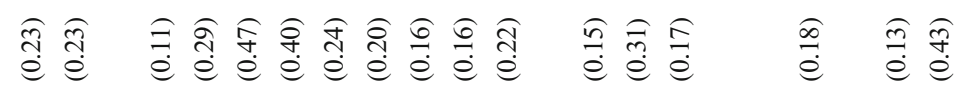

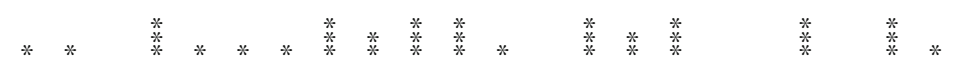

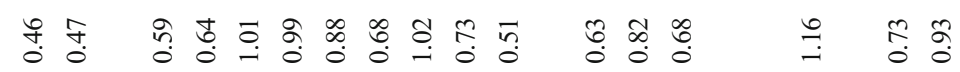

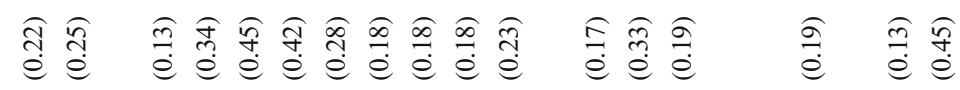

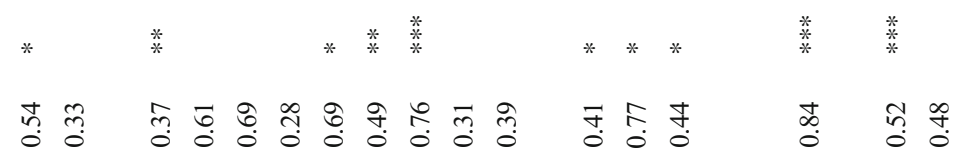

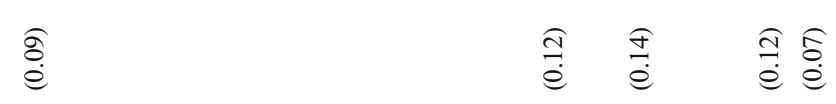

光

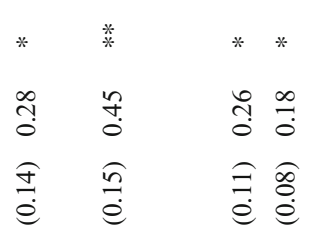

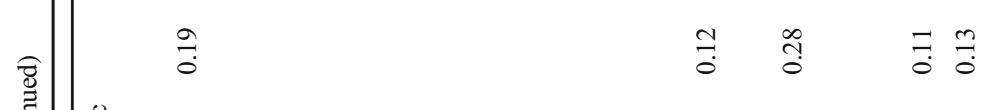

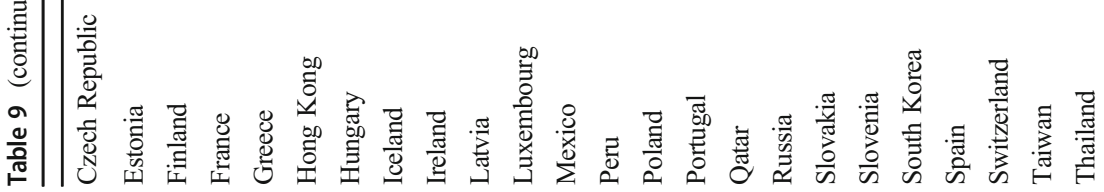




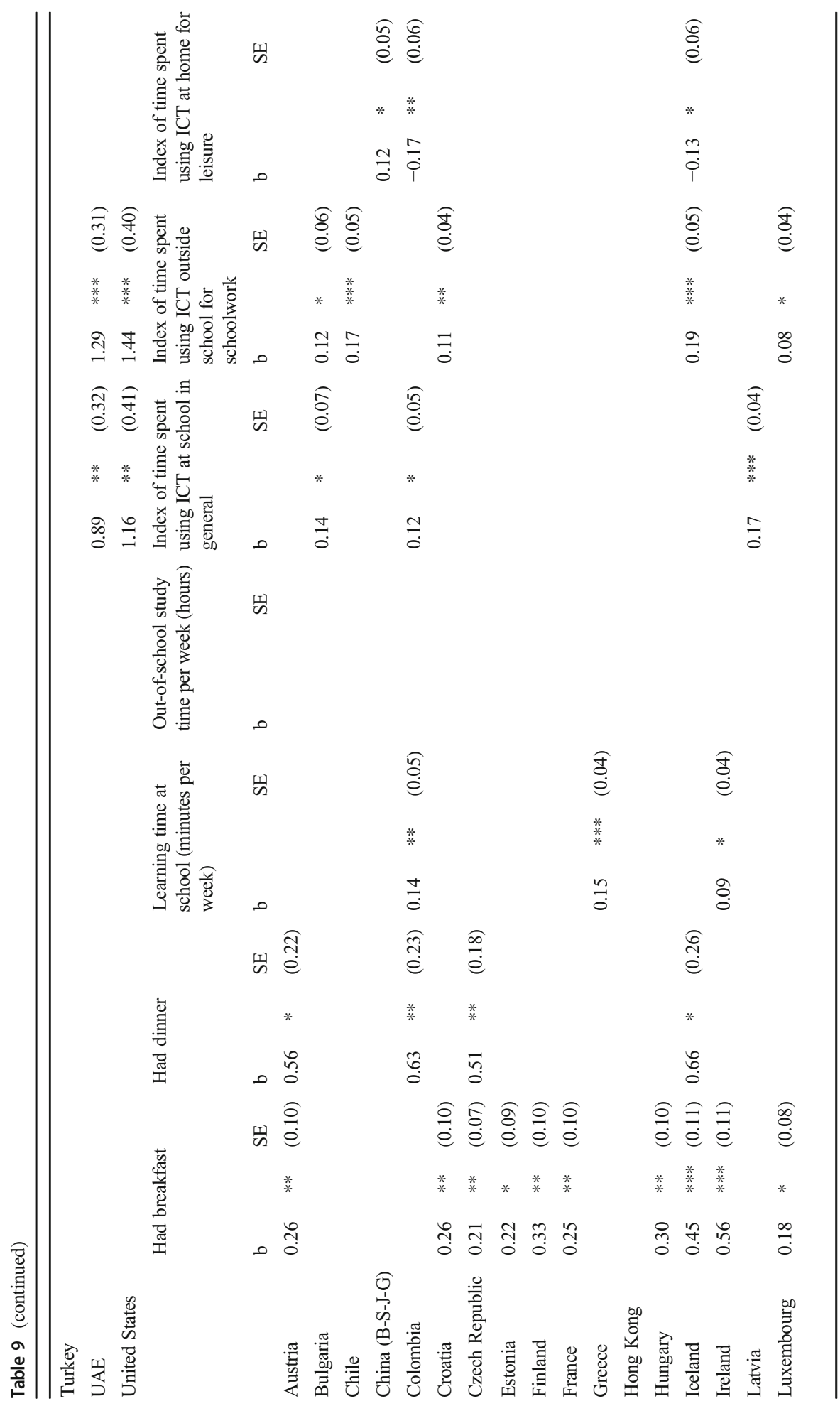




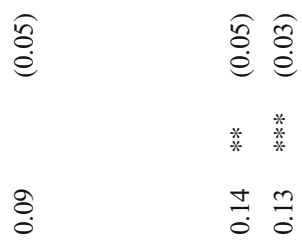

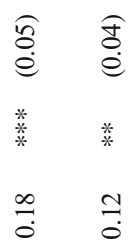

จी

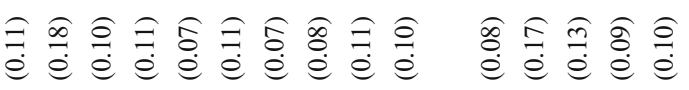

*

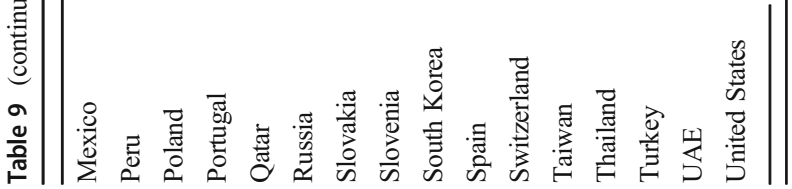

黑 Springer 


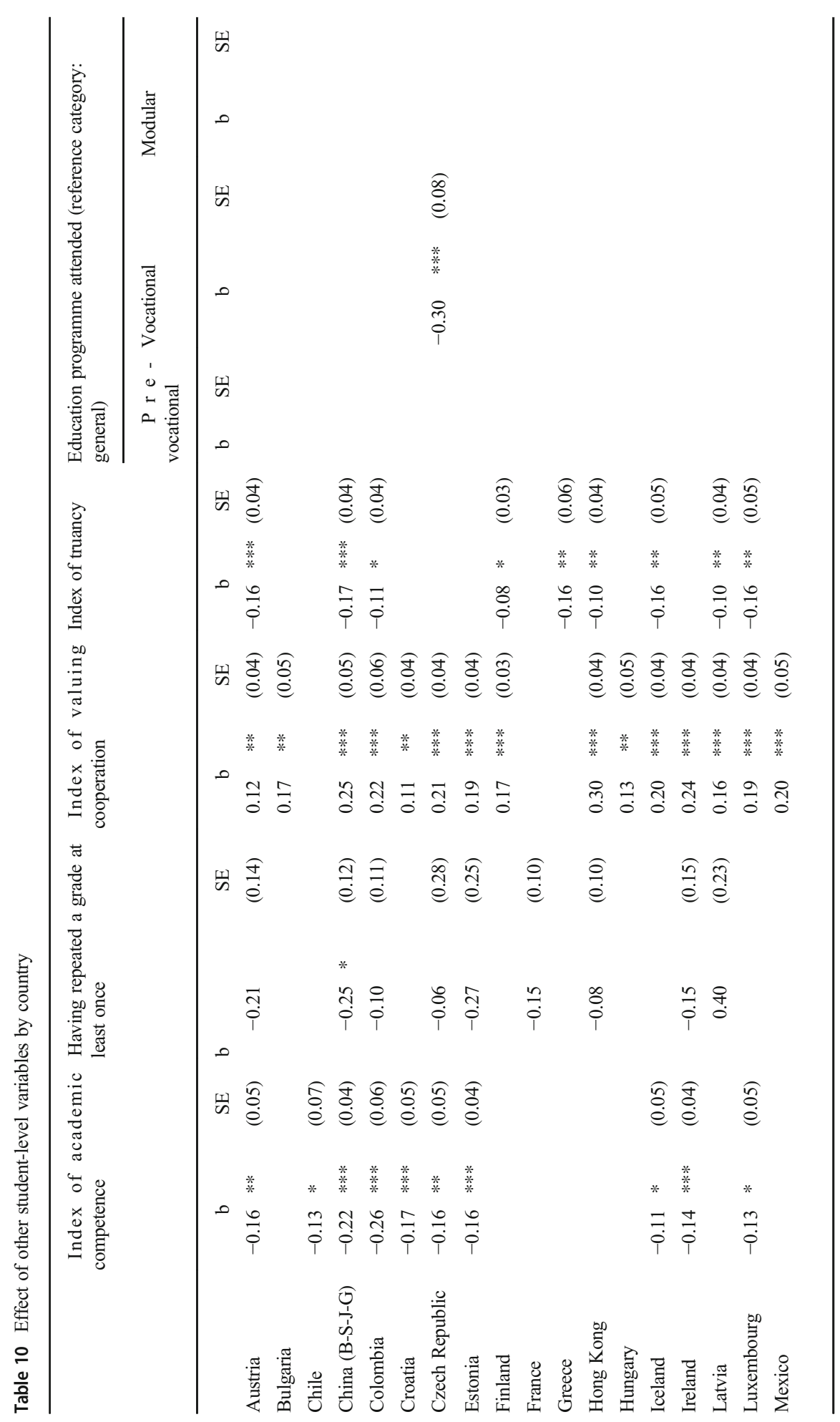




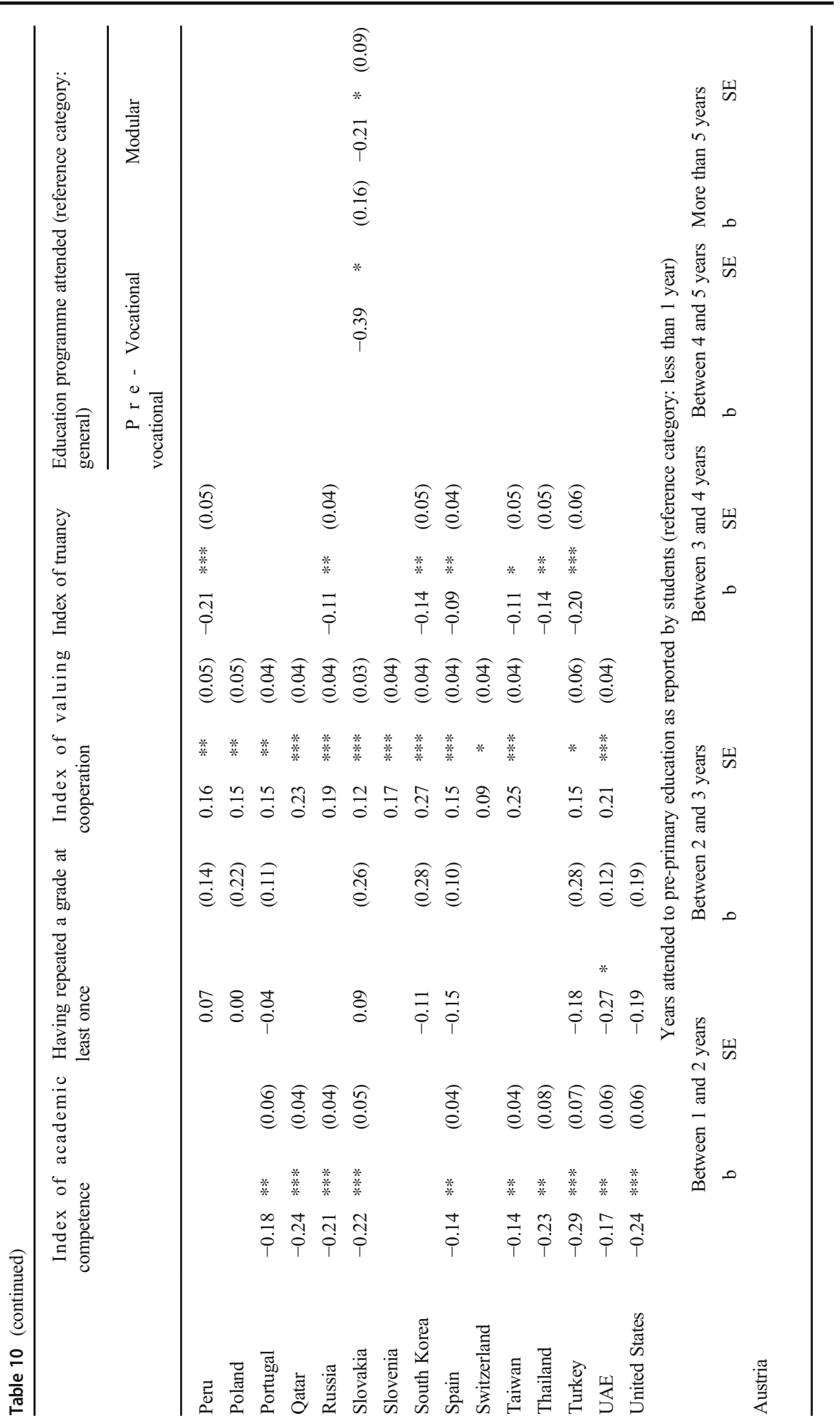




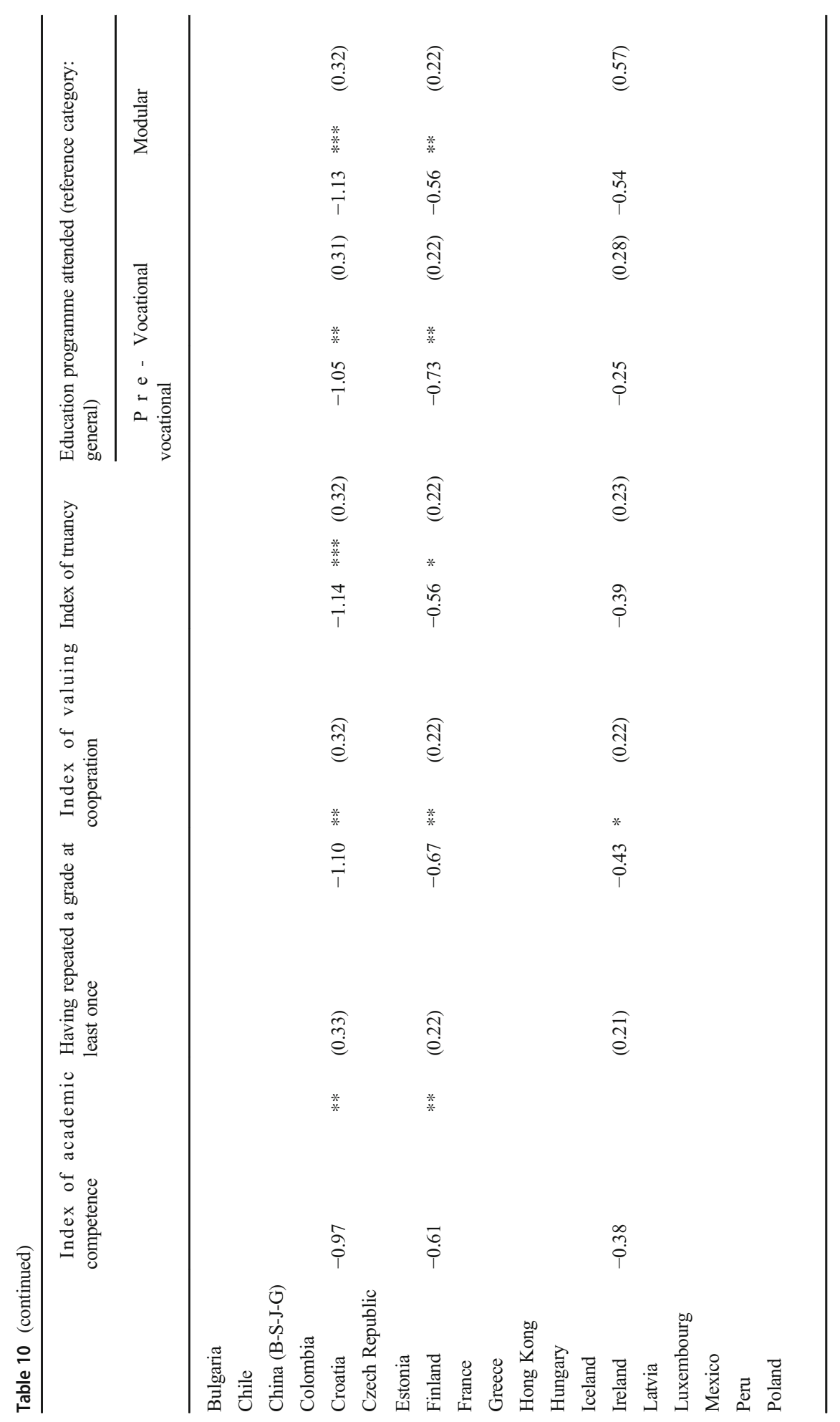




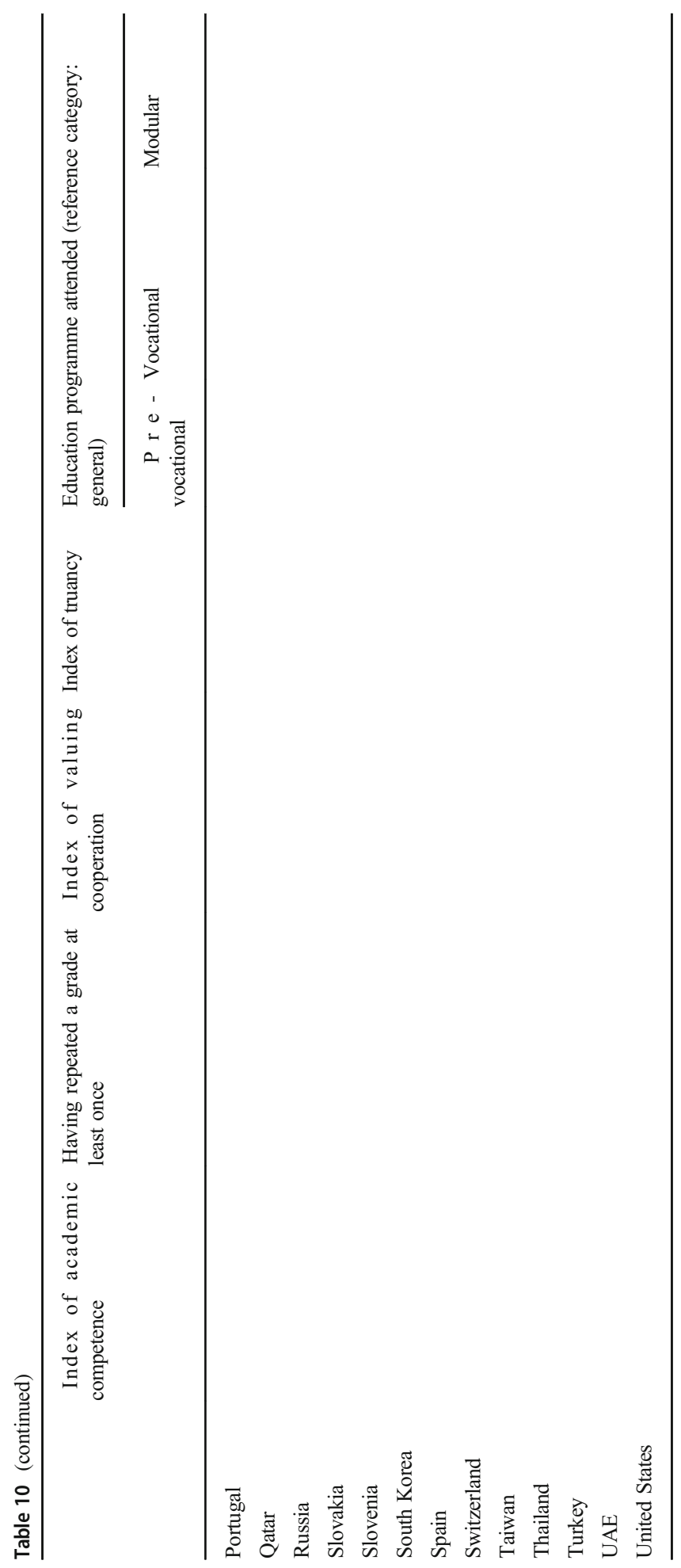

照 Springer 


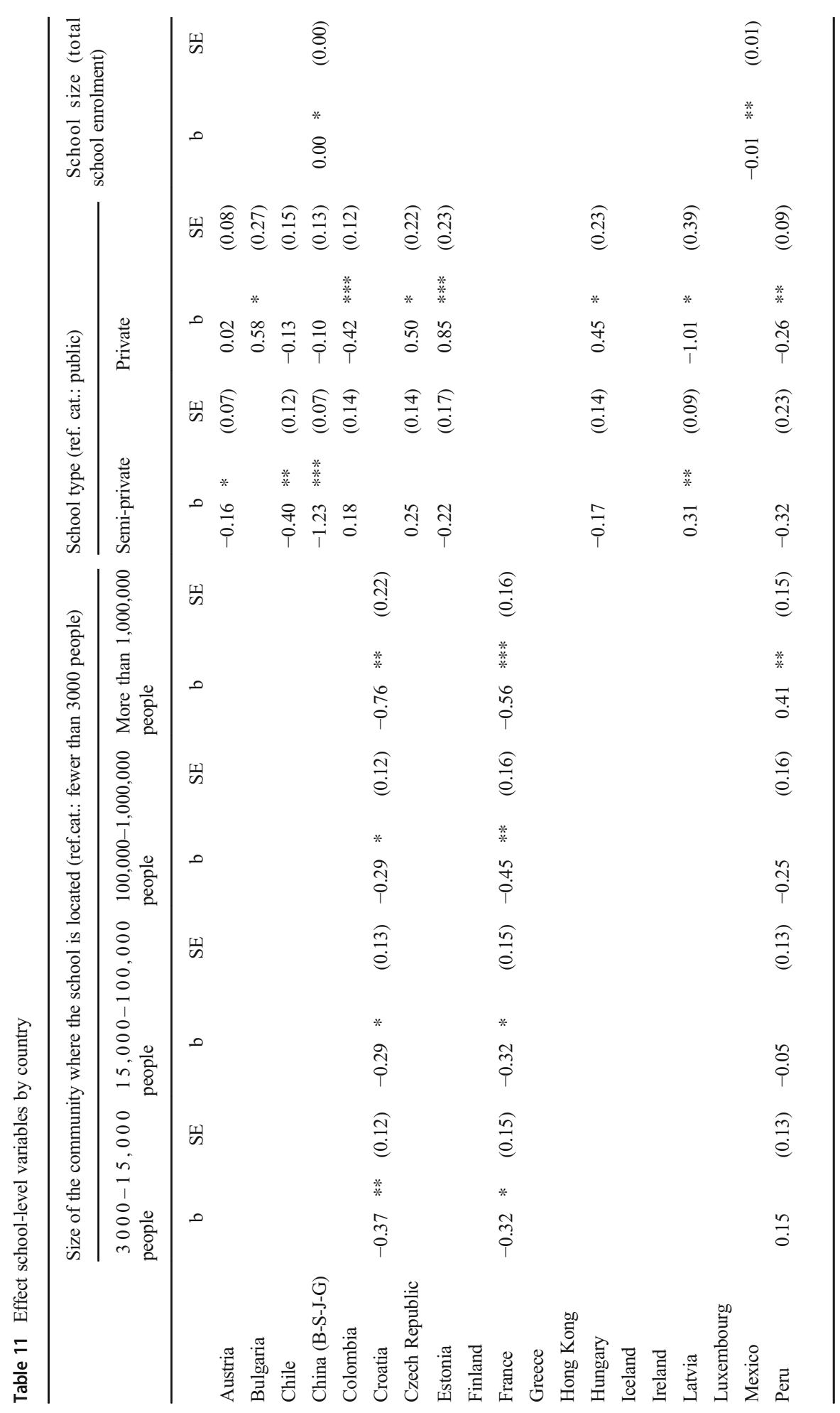




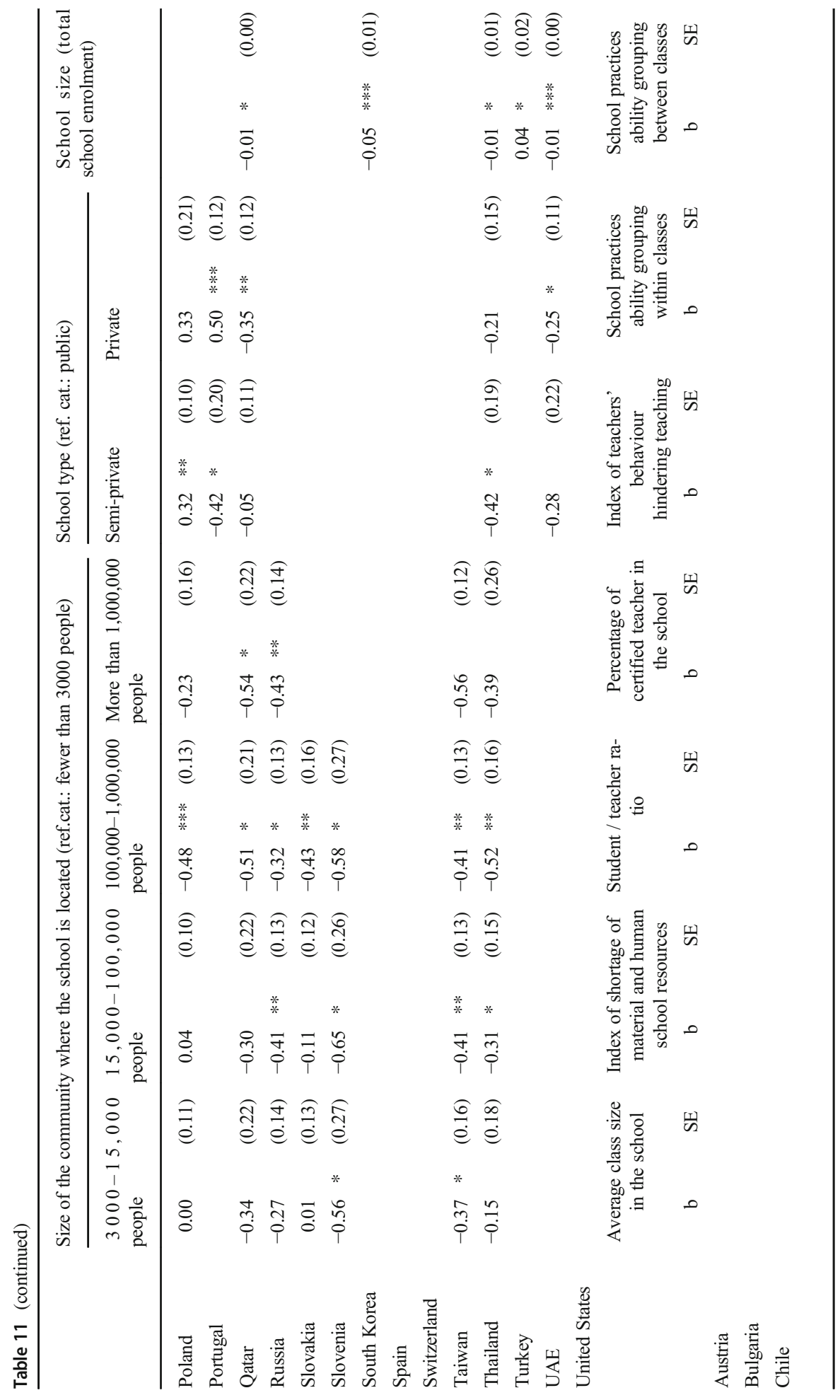




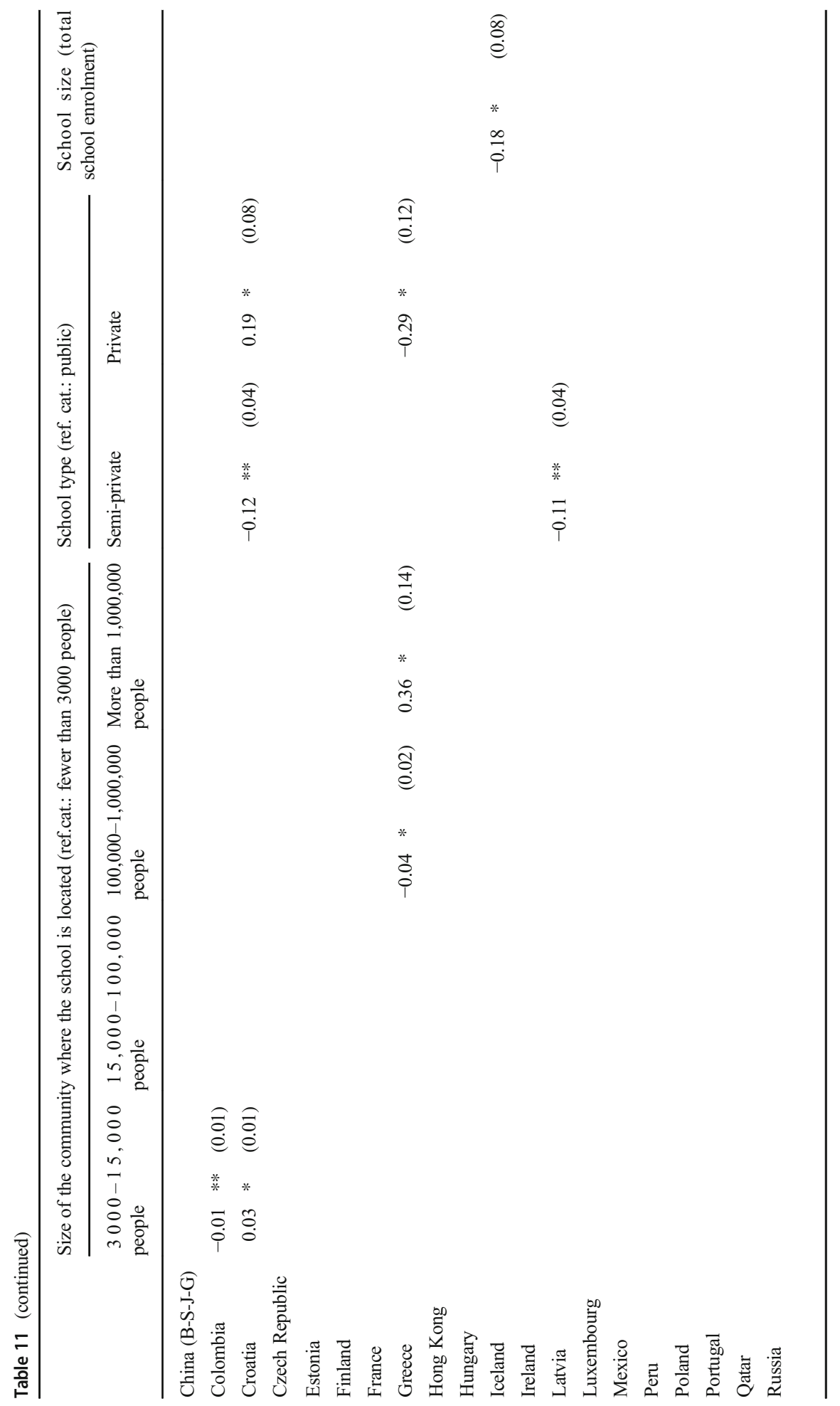




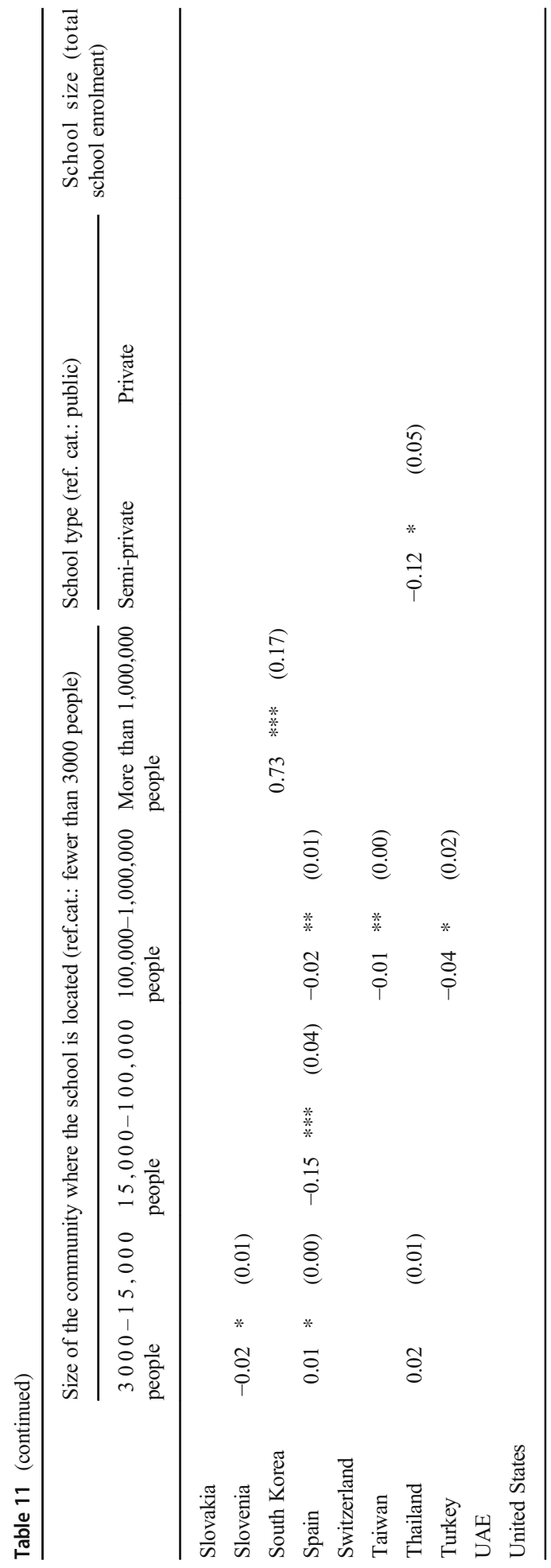


Open Access This article is licensed under a Creative Commons Attribution 4.0 International License, which permits use, sharing, adaptation, distribution and reproduction in any medium or format, as long as you give appropriate credit to the original author(s) and the source, provide a link to the Creative Commons licence, and indicate if changes were made. The images or other third party material in this article are included in the article's Creative Commons licence, unless indicated otherwise in a credit line to the material. If material is not included in the article's Creative Commons licence and your intended use is not permitted by statutory regulation or exceeds the permitted use, you will need to obtain permission directly from the copyright holder. To view a copy of this licence, visit http://creativecommons.org/licenses/by/4.0/.

\section{References}

Alikasifoglu, M., Erginoz, E., Ercan, O., Uysal, O., \& Albayrak-Kaymak, D. (2007). Bullying behaviours and psychosocial health: Results from a cross-sectional survey among high school students in Istanbul, Turkey. European Journal of Pediatrics, 166(12), 1253-1260.

Amin, S., \& Chandrasekhar, S., (2012) Looking beyond universal primary education: Gender differences in time use among children in rural Bangladesh. Population Council. Available at: https:/www.researchgate. net/publication/46476484_Looking_Beyond_Universal_Primary_Education_Gender_Differences_in_ Time_Use_among_Children_in_Rural_Bangladesh (Accessed: 5 April 2019), 8, 23, 38.

Ben-Arieh, A. (2005). Where are the children? Children's role in measuring and monitoring their well-being. Social Indicators Research. Kluwer Academic Publishers, 74(3), 573-596.

Ben-Arieh, A. (2008). The child indicators movement: Past, present, and future. Child Indicators Research. Springer Netherlands, 1(1), 3-16.

Bokhorst, C, L., Sumter, S, R. \& Westenberg, P, M. (2010). Social support from parents, friends, classmates, and teachers in children and adolescents aged 9 to 18 years: Who is perceived as Most supportive? Social development. John Wiley \& Sons, 1td (10.1111), 19(2), pp. 417-426.

Boniel-Nissim, M., Tabak, I., Mazur, J., Borraccino, A., Brooks, F., Gommans, R., van der Sluijs, W., Zsiros, E., Craig, W., Harel-Fisch, Y., \& Finne, E. (2015). Supportive communication with parents moderates the negative effects of electronic media use on life satisfaction during adolescence. International Journal of Public Health, 60(2), 189-198.

Bouakaz, L., (2007). Parental involvement in school : What promotes and what hinders parental involvement in an urban school, Malmö studies in educational sciences : Doctoral dissertation series;30, Lärarutbildningen, Malmö högskola.

Bradshaw, J. (2015). Subjective well-being and social policy: Can nations make their children happier? Child indicators research. Springer Netherlands, 8(1), 227-241.

Bradshaw, J., \& Rees, G. (2017). Exploring national variations in child subjective well-being. Children and Youth Services Review. Pergamon, 80, 3-14.

Bradshaw, J., Crous, G., \& Turner, N. (2017). Comparing children's experiences of schools-based bullying across countries. Children and Youth Services Review. Pergamon, 80, 171-180.

Bücker, S., Nuraydin, S., Simonsmeier, B. A., Schneider, M., \& Luhmann, M. (2018). Subjective well-being and academic achievement: A meta-analysis. Journal of Research in Personality, Academic Press, 74, 83-94.

Cantril, H. (1966). The pattern of human concerns. New Brunswick N.J.: Rutgers University Press. Available at: https://www.worldcat.org/title/pattern-of-human-concerns/oclc/2082808 (Accessed: 19 February 2019).

Casas, F. (2011). Subjective social indicators and child and adolescent well-being. Child indicators research. Springer Netherlands, 4(4), 555-575.

Casas, F., González-Carrasco, M., \& Luna, X. (2018). Children's rights and their subjective well-being from a multinational perspective. European journal of education. John Wiley \& Sons, ltd (10.1111), 53(3), 336-350.

Chu, P. S., Saucier, D. A., \& Hafner, E. (2010). Meta-analysis of the relationships between social support and well-being in children and adolescents. Journal of social and clinical psychology. Guilford Publications Inc., 29(6), 624-645.

Clair, A. (2014). The effects of schooling and education policy on the subjective well-being of children: A comparative study'. University of York. Available at: http://etheses.whiterose.ac.uk/8120/ (Accessed: 19 February 2019).

Corsano, P., Majorano, M. \& Champretavy, L. (2006). Psychologicalwell-being in adolescence: The contribution of interpersonal relations and experience of being alone. Adolescence. Libra publishers, 41(162), p. 
341. Available at: https:/www.questia.com/library/journal/1G1-150966285/psychological-well-being-inadolescence-the-contribution (Accessed: 4 April 2019).

Cotterell, J. \& Cotterell, J. (2007). Social networks in youth and adolescence. Routledge. Available at: https://www. routledge.com/Social-Networks-in-Youth-and-Adolescence/Cotterell/p/book/9780415359504 (Accessed: 4 April 2019).

Currie, C. (2012). Social determinants of health and well-being among young people : Health behaviour in school-aged children (HBSC) study : International report from the 2009/2010 survey. World Health Organization, Regional Office for Europe.

Silva, L, C. da \& Matos, D, A, S. (2017). Indiscipline in Pisa: between intra- and extra-school factors. Available at: http://www.repositorio.ufop.br/handle/123456789/9511 (Accessed: 20 February 2019).

Danielsen, A. G., Breivik, K., \& Wold, B. (2011). Do perceived academic competence and school satisfaction mediate the relationships between perceived support provided by teachers and classmates, and academic initiative? Scandinavian Journal of Educational Research, 55(4), 379-401.

Demaray, M. K., \& Malecki, C. (2003). Perceptions of the frequency and importance of social support by students classified as victims, bullies, and bully/victims in an urban middle school. School Psychology Review, 32(3), 471-489.

Diener, E. (1984). Subjective well-being. Psychological Bulletin, 95(3), 542-575.

Diener, E., Suh, E. M., Lucas, R. E., \& Smith, H. L. (1999). Subjective well-being: Three decades of progress. Psychological Bulletin, 125(2), 276-302. https://doi.org/10.1037/0033-2909.125.2.276.

Diener, E., Lucas, R., \& Oishi, S. (2002). Subjective well-being: The science of happiness and life satisfaction. In C. R. Snyder \& S. J. Lopez (Eds.), The handbook of positive psychology (pp. 63-73). New York: Oxford University Press.

Dinisman, T., \& Ben-Arieh, A. (2016). The characteristics of Children's subjective well-being. Social Indicators Research, 126(2), 555-569.

Diseth, A., \& Samdal, O. (2014). Autonomy support and achievement goals as predictors of perceived school performance and life satisfaction in the transition between lower and upper secondary school. Social Psychology of Education, 17(2), 269-291.

Dornan, P. \& Woodhead, M. (2015). How inequalities develop through childhood: life course evidence from the young lives cohort study. Available at: www.unicef-irc.org (Accessed: 4 April 2019).

Easterlin, R, A. (1974). Does economic growth improve the human lot? Some empirical evidence. Nations and households in economic growth. Academic press, pp. 89-125.

Eid, M., \& Diener, E. (2004). Global judgments of subjective well-being: Situational variability and Longterm stability. Social indicators research. Kluwer Academic Publishers, 65(3), 245-277.

Eriksson, U., Hochwälder, J., \& Sellström, E. (2011). Perceptions of community trust and safety - consequences for children's well-being in rural and urban contexts. Acta Paediatrica, 100(10), 1373-1378.

Ersado, L. (2005). Child labor and schooling decisions in urban and rural areas: Comparative evidence from Nepal, Peru, and Zimbabwe. World Development. Pergamon, 33(3), 455-480.

Fergusson, D. M., McLeod, G. F., Horwood, L. J., Swain, N. R., Chapple, S., \& Poulton, R. (2015). Life satisfaction and mental health problems (18 to 35 years). Psychological Medicine, 45(11), 2427-2436.

Ferrer-i-Carbonell, A., \& Frijters, P. (2004). How important is methodology for the estimates of the determinants of happiness? The economic journal. John Wiley \& Sons, ltd (10.1111), 114(497), 641-659.

Flaspohler, P. D., Elfstrom, J. L., Vanderzee, K. L., Sink, H. E., \& Birchmeier, Z. (2009). Stand by me: The effects of peer and teacher support in mitigating the impact of bullying on quality of life. Psychology in the schools. John Wiley \& Sons, Ltd, 46(7), 636-649.

Furman, W., \& Buhrmester, D. (1992). Age and sex differences in perceptions of networks of personal relationships. Child development, 63(1), 103-115 Available at: http://www.ncbi.nlm.nih. gov/pubmed/1551320 (Accessed: 4 April 2019).

García-Moya, I., Brooks, F., Morgan, A., \& Moreno, C. (2014). Subjective well-being in adolescence and teacher connectedness: a health asset analysis. Health Education Journal, 74(6), 641-654.

Gillies, R. M. (2004). The effects of cooperative learning on junior high school students during small group learning. Learning and Instruction, 14(2), 197-213.

Gilman, R., \& Huebner, S. (2003). A review of life satisfaction research with children and adolescents. School Psychology Quarterly, 18(2), 192-205.

Glăveanu, V., Branco, A., \& Neves-Pereira, M. (2016). Creativity and Prosocial values: Nurturing cooperation within the classroom. In R. Beghetto \& J. Kaufman (Eds.), Nurturing Creativity in the Classroom (current perspectives in social and behavioral sciences, pp. 287-307). Cambridge: Cambridge University Press. doi:https://doi.org/10.1017/9781316212899.017.

González, M., Gras, M. E., Malo, S., Navarro, D., Casas, F., \& Aligue, M. (2015). Adolescents' perspective on their participation in the family context and its relationship with their subjective well-being. Child indicators research. Springer Netherlands, 8(1), 93-109. 
Goswami, H. (2012). Social relationships and Children's subjective well-being. Social indicators research. Springer Netherlands, 107(3), 575-588.

Govender, K., Reardon, C., Quinlan, T., \& George, G. (2014). Children's psychosocial wellbeing in the context of HIV/AIDS and poverty: A comparative investigation of orphaned and non-orphaned children living in South Africa. BMC public health, 14(1), 615.

Haanpää, L., Ursin, P., Nermes, M., Kaljonen, A., \& Isolauri, E. (2018). Association of allergic diseases with children's life satisfaction: Population-based study in Finland. BMJ Open, 8, 19281.

Helliwell, J, F., Layard, R., \& Sachs, J. (2012) World happiness report 2012. New York: UN Sustainable Development Solutions Network. Available at: http://worldhappiness.report/ed/2012/ (Accessed: 4 April 2019).

Helliwell, J. F., Layard, R., \& Sachs, J. (2013). World happiness report 2013. New York: UN Sustainable Development Solutions Network. Available at: http://worldhappiness.report/ed/2013/.

Helliwell, J, F., Layard, R., \& Sachs, J. (2015) World happiness report 2015. New York: UN Sustainable Development Solutions Network. Available at: http:/worldhappiness.report/ed/2015/ (Accessed: 4 April 2019).

Helliwell, J, F., Layard, R., \& Sachs, J. (2016) World happiness report 2016. New York: UN Sustainable Development Solutions Network. Available at: http://worldhappiness.report/ed/2016/ (Accessed: 4 April 2019).

Helliwell, J, F., Layard, R., \& Sachs, J. (2017) World happiness report 2017. New York: UN Sustainable Development Solutions Network. Available at: http:/worldhappiness.report/ed/2017/ (Accessed: 4 April 2019).

Helliwell, J, F., Layard, R., \& Sachs, J. (2018) World happiness report 2018. New York: UN Sustainable Development Solutions Network. Available at: http:/worldhappiness.report/ed/2018/ (Accessed: 4 April 2019).

Helliwell, J, F., Layard, R., \& Sachs, J. (2019) World happiness report 2019. New York: UN Sustainable Development Solutions Network. Available at: http://worldhappiness.report/ed/2019/ (Accessed: 4 April 2019).

Hicks, S., Tinkler, L., \& Allin, P. (2013). Measuring subjective well-being and its potential role in policy: Perspectives from the UK Office for National Statistics. Social indicators research. Springer Netherlands, 114(1), 73-86.

Hox, J. J. (2010). Multilevel analysis : Techniques and applications. Routledge.

Iannotti, R. J., Janssen, I., Haug, E., Kololo, H., Annaheim, B., \& Borraccino, A. (2009). Interrelationships of adolescent physical activity, screen-based sedentary behaviour, and social and psychological health. International Journal of Public Health, 54(S2), 191-198.

Jerrim, J., Lopez-Agudo, L. A., Marcenaro-Gutierrez, O. D., \& Shure, N. (2017). What happens when econometrics and psychometrics collide? An example using the PISA data. Economics of Education Review. Pergamon, 61, 51-58.

Kaye-Tzadok, A., Kim, S. S., \& Main, G. (2017). Children's subjective well-being in relation to gender — What can we learn from dissatisfied children? Children and youth services review. Pergamon, 80, 96-104.

Kleszczewska, D., Dzielska, A., Salonna, S., \& Mazur, J. (2018). The association between physical activity and general life satisfaction in lower secondary school students: The role of individual and family factors. Community mental health journal. Springer US, 54(8), 1245-1252.

Klocke, A., Clair, A., \& Bradshaw, J. (2014). International variation in child subjective well-being. Child indicators research. Springer Netherlands, 7(1), 1-20.

Kutsar, D., \& Kasearu, K. (2017). Do children like school - Crowding in or out? International comparison of children's perspectives. Children and Youth Services Review. Pergamon, 80, 140-148.

Larson, R. W., \& Verma, S. (1999). How children and adolescents spend time across the world: Work, play, and developmental opportunities. Psychological bulletin, 125(6), 701-736 Available at: http://www.ncbi. nlm.nih.gov/pubmed/10589300 (Accessed: 4 April 2019).

Laukaityte, I., \& Wiberg, M. (2018). Importance of sampling weights in multilevel modeling of international large-scale assessment data. Communications in Statistics - theory and methods. Taylor \& Francis, 47(20), 4991-5012.

Lavy, V. (2015). Do differences in schools' instruction time explain international achievement gaps? Evidence from developed and developing countries. The Economic Journal. John Wiley \& Sons, ltd (10.1111), 125(588), F397-F424.

Lawler, M. J., Newland, L. A., Giger, J. T., Roh, S., \& Brockevelt, B. L. (2017). Ecological, relationshipbased model of Children's subjective well-being: Perspectives of 10-year-old children in the United States and 10 other countries', child indicators research. Springer Netherlands, 10(1), 1-18.

Layard, R. (2005). Happiness: Lessons from a new science. New York, NY, US: Penguin books/penguin group (USA).

Lee, B. J., \& Yoo, M. S. (2015). Family, school, and community correlates of Children's subjective wellbeing: An international comparative study. Child Indicators Research. Springer Netherlands, 8(1), 151175 . 
Lew, D., Xian, H., Qian, Z., Vaughn, M. G. (2018). Examining the relationships between life satisfaction and alcohol, tobacco and marijuana use among school-aged children. Journal of Public Health 41(2), 346353

Looze, M. E., Huijts, T., Stevens, G. W. J. M., Torsheim, T., \& Vollebergh, W. A. M. (2018). The happiest kids on earth. Gender equality and adolescent life satisfaction in Europe and North America. Journal of Youth and Adolescence. Springer US, 47(5), 1073-1085.

Marques, A., Mota, J., Gaspar, T., \& de Matos, M. G. (2017). Associations between self-reported fitness and self-rated health, life-satisfaction and health-related quality of life among adolescents. Journal of Exercise Science \& Fitness. Elsevier, 15(1), 8-11.

Marshall, S. K. (2004). Relative contributions of perceived mattering to parents and friends in predicting adolescents' psychological well-being. Perceptual and Motor Skills, 99(2), 591-601.

Martinez, B., Moreno, D., Amador, L. V., \& Orford, J. (2011). School victimization among adolescents. An analysis from an ecological perspective. Psychosocial Intervention. Elsevier, 20(2), 149-160.

McNeely, C., \& Falci, C. (2004). School connectedness and the transition into and out of health-risk behavior among adolescents: A comparison of social belonging and teacher support. The journal of school health, 74(7), 284-292 Available at: http://www.ncbi.nlm.nih.gov/pubmed/15493705 (Accessed: 4 April 2019).

Moore, G, F., Cox, R., Evans, R, E., Hallingberg, B., Hawkins, J., Littlecott, H, J., Long, S, J., \& Murphy, S. (2018) School, peer and family relationships and adolescent substance use, Subjective Wellbeing and Mental Health Symptoms in Wales: a Cross Sectional Study. Child Indicators Research. Springer Netherlands, 11(6), pp. 1951-1965.

Moreno, A. (2017). The role of family policy in explaining the international variation in child subjective wellbeing. Social indicators research. Springer Netherlands, 134(3), 1173-1194.

Navarro, R., Ruiz-Oliva, R., Larrañaga, E., \& Yubero, S. (2015). The impact of Cyberbullying and social bullying on optimism, global and school-related happiness and life satisfaction among 10-12-year-old schoolchildren. Applied Research in Quality of Life. Springer Netherlands, 10(1), 15-36.

Newland, L. A., Lawler, M. J., Giger, J. T., Roh, S., \& Carr, E. R. (2015). Predictors of Children's subjective well-being in rural communities of the United States. Child indicators research. Springer Netherlands, 8(1), 177-198.

Newland, L. A., Lawler, M. J., Giger, J. T., Roh, S., \& Carr, E. R. (2018). Multilevel analysis of child and adolescent subjective well-being across 14 countries: Child- and country-level predictors. Child Development, 90(2), 395-413.

Oberle, E., Schonert-Reichl, K. A., \& Zumbo, B. D. (2011). Life satisfaction in early adolescence: Personal, neighborhood, school, family, and peer influences. Journal of Youth and Adolescence, 40(7), 889-901.

OECD (2009) PISA data analysis manual: SPSS and SAS, Second Edition. PISA, OECD Publishing, Paris, http://www.oecd.org/pisa/pisaproducts/pisadataanalysismanualspssandsassecondedition.htm (Accessed: 20 February 2019).

OECD (2011) How's life? 2011: Measuring well-being. OECD Publishing, Paris, https://oi.org/10.1787 /9789264121164-en.

OECD (2013) How's life? 2013: Measuring well-being. OECD Publishing, Paris, https://oi.org/10.1787 /9789264201392-en.

OECD (2015) How's life? 2015: Measuring well-being. OECD Publishing, Paris, https://oi.org/10.1787 how_life-2015-en.

OECD (2017a) PISA 2015 results (volume III): Students' well-being. PISA, OECD Publishing, Paris, https://doi.org/10.1787/9789264273856-en (Accessed: 20 February 2019).

OECD (2017b) PISA 2015 technical report. PISA, OECD Publishing, Paris. http://www.oecd. org/pisa/sitedocument/PISA-2015-technical-report-final.pdf (Accessed: 20 February 2019).

OECD (2017c) How's life? 2017: Measuring well-being. OECD Publishing, Paris, https://doi.org/10.1787 how life-2017-en.

OPHI (2020). Bhutan's gross national happiness index Available at: https://ophi.org.uk/policy/nationalpolicy/gross-national-happiness-index/ (Accessed: 21 February 2019).

Park, S., \& Holloway, S. D. (2013). No parent left behind: Predicting parental involvement in Adolescents' education within a Sociodemographically diverse population. The Journal of Educational Research, 106(2), 105-119. https://doi.org/10.1080/00220671.2012.667012.

Powdthavee, N., \& Vernoit, J. (2013). Parental unemployment and children's happiness: A longitudinal study of young people's well-being in unemployed households. Labour economics. NIH Public Access, 24, 253-263.

Proctor, C., Linley, P. A., \& Maltby, J. (2009). Youth life satisfaction measures: A review. The journal of positive psychology. Routledge, 4(2), 128-144. 
Proctor, C., Linley, P. A., \& Maltby, J. (2010). Very happy youths: Benefits of very high life satisfaction among adolescents. Social indicators research. Springer Netherlands, 98(3), 519-532.

Rabe-Hesketh, S., \& Skrondal, A. (2006). Multilevel modelling of complex survey data. Journal of the Royal Statistical Society: Series A (Statistics in Society), 169(4), 805-827.

Rees, G. (2017). Children's activities and time use: Variations between and within 16 countries. Children and Youth Services Review, 80, 78-87.

Rees, G. and Main, G. (2015). Children's views on their lives and well-being in 15 countries: A report on the Children's Worlds survey, 2013-14. Available at: www.isciweb.org (Accessed: 4 April 2019).

Rees, G., Goswami, H., Pople, L., Bradshaw, J. Keung, A., \& Main, G. (2012). The Good Childhood report 2012 | The Children's Society. Available at: https:/www.childrenssociety.org.uk/what-we-do/resourcesand-publications/publications-library/good-childhood-report-2012 (Accessed: 5 April 2019).

Rose, T., Sean, J., Shields, J., \& Caldwell, C. H. (2014). Social integration and the mental health of black adolescents. Child development. NIH Public Access, 85(3), 835-841.

Samdal, O., Nutbeam, D., Wold, B., \& Kannas, L. (1998). Achieving health and educational goals through schools-A study of the importance of the school climate and the students' satisfaction with school. Health education research. Narnia, 13(3), 383-397.

Savahl, S., Montserrat, C., Casas, F., Adams, S., Tiliouine, H., Benninger, E., \& Jackson, K. (2019). Children's experiences of bullying victimization and the influence on their subjective well-being: A multinational comparison. Child Development, 90(2), $414-431$.

Schirripa, F., Salvati, N., D’Agostino, A., \& Nicaise, I. (2018). The use of sampling weights in the M-quantile random-effects regression: an application to PISA mathematics scores. Available at: http://arxiv. org/abs/1802.08004 (Accessed: 20 February 2019).

Snijders, T. A. B., \& Bosker, R. J. (1994). Modeled variance in two-level models. Sociological Methods \& Research. SAGE periodical press, 22(3), 342-363.

Snijders, T, A, B. \& Bosker, R, J. (1999). Multilevel analysis: An introduction to basic and advanced multilevel modeling. SAGE Publications Ltd.

Stiglitz, J, E. (2009). Report by the Commission on the Measurement of Economic Performance and Social Progress. Available at: www.stiglitz-sen-fitoussi.fr (Accessed: 21 February 2019).

Thorsteinsson, E. B., Loi, N. M., Sveinbjornsdottir, S., \& Arnarsson, A. (2017). Sexual orientation among Icelandic year 10 adolescents: Changes in health and life satisfaction from 2006 to 2014. Scandinavian Journal of Psychology, 58(6), 530-540.

Tiliouine, H. (2015). School bullying victimisation and subjective well-being in Algeria. Child indicators research. Springer Netherlands, 8(1), 133-150.

Tsai, S. L., Smith, M. L., \& Hauser, R. M. (2018). Gender gaps in student academic achievement and inequality, in, pp. 181-218. John Wiley \& Sons, ltd (10.1111), 169(4), 805-827.

UAE Government (2020). Happiness. The Official Portal of the UAE Government. Available at: https://government.ae/en/about-the-uae/the-uae-government/government-of-future/happiness (Accessed: 21 February 2019).

United Nations (1989). Convention on the rights of the child. Available at: https://downloads.unicef.org. uk/wp-content/uploads/2010/05/UNCRC_united_nations_convention_on_the_rights_of_the_child.pdf? ga=2.257932747.1956100419.1551090697-1245006073.1551090697 (Accessed: 25 Fe - bruary 2019).

van Hek, M., Kraaykamp, G., \& Pelzer, B. (2018). Do schools affect girls' and boys' reading performance differently? A multilevel study on the gendered effects of school resources and school practices. School Effectiveness and School Improvement. Routledge, 29(1), 1-21.

West, B. T., Welch, K. B., \& Gatecki, A. T. (2007). Linear mixed models. Boca Raton: Chapman \& Hall. Wyness, M. (2014). Children, family and the state: revisiting public and private realms. Sociology 48(1), 5974.

Publisher's Note Springer Nature remains neutral with regard to jurisdictional claims in published maps and institutional affiliations.

\section{Affiliations}

\section{Jose Marquez ${ }^{1} \cdot$ Gill Main $^{1}$}

1 School of Education, University of Leeds, Hillary Place, LS2 9JT Leeds, UK 